Journal of Geophysical Research: Earth Surface

\section{RESEARCH ARTICLE \\ 10.1002/2017JF004227 \\ Shore and bar cross-shore migration, rotation, and breathing processes at an embayed beach}

Key Points:

- Shoreline and bar migrations, mainly

simultaneous, dominate the 2-D

variations of morphology

- Shoreline and bar rotations

do not respond to the same

environmental drivers but often occur simultaneously

- Barline breathing occurs with an overall retreat or progradation of the shoreline and barline

\section{Correspondence to:}

B. Blossier,

bblossier@marum.de

\section{Citation:}

Blossier, B., K. R. Bryan, C. J. Daly, and C. Winter (2017), Shore and bar cross-shore migration, rotation, and breathing processes at an embayed beach, J. Geophys. Res. Earth Surf., 122, 1745-1770, doi:10.1002/2017JF004227.

Received 23 JAN 2017 Accepted 26 JUL 2017 Accepted article online 11 AUG 2017 Published online 6 OCT 2017

Abstract A principal component analysis (PCA) is used to decompose data on the coupled move at the same time, and nonsimultaneous modes, where the shore moves independently from the bar, and vice versa. Two simultaneous modes accounting for $65 \%$ of the variance of the shoreline and barline dominate the system. One mode describes inverse shoreline and sandbar cross-shore migrations (alongshore averaged), occurring with simultaneous rotations in the same direction. The other mode accounts for migration in the same direction accompanied by variations of the barline curvature (similar to "breathing modes" previously described in embayed beach shoreline modeling studies). Two nonsimultaneous modes of lesser importance account separately for independent shoreline and barline by four standard equilibrium models simulating shore and sandbar cross-shore migrations and rotations

\author{
B. Blossier ${ }^{(\mathbb{D}}$, K. R. Bryan ${ }^{2}\left(\mathbb{D}\right.$, C. J. Daly ${ }^{1,3}\left(\mathbb{D}\right.$, and C. Winter ${ }^{1}(\mathbb{D}$ \\ ${ }^{1}$ MARUM, Center for Marine Environmental Sciences, University of Bremen, Bremen, Germany, ${ }^{2}$ Coastal Marine Group, \\ Faculty of Science and Engineering, University of Waikato, Hamilton, New Zealand, ${ }^{3}$ Institut Universitaire Européen de la \\ Mer, UMR 6538, LGO, Plouzané, France
} morphodynamics of the shoreline and nearshore sandbar of a typical single-barred embayed beach (Tairua Beach, New Zealand). Dynamic patterns are classified into simultaneous modes, where the bar and shoreline rotations ( 10 to $15 \%$ of the variance explained). A PCA applied to the shore and sandbar behaviors modeled show that these are interrelated because of a correlation between wave energy and direction. Shore and bar rotations are coupled partially because the shape of the bay induces a correlation of their respective drivers, the wave angle of incidence and the alongshore gradient of wave energy. However, this correlation depends on the wave energy. This, in combination with different shore and sandbar response times (quantified using the models), also explains the independent rotations reflected by the nonsimultaneous modes.

\section{Introduction}

Embayed beaches are landforms typically found along rugged coastlines exhibiting rocky outcrops. Such headland-bay morphology, accounting for an estimated 50\% of the world's coastline [Short, 1999], is also common in urban areas, where groins and breakwaters constitute artificial headlands that embay beach sediments (e.g., in Barcelona, Spain [Ojeda and Guillén, 2008]). Over the past decades, reduced sediment supply often related to river damming [Chaibi and Sedrati, 2009], and the progressive construction of dwellings on coastal dunes [Healy and Soomere, 2008], has increased the risks related to coastal erosion, in particular, in embayed environments [Flor and Flor-Blanco, 2005; Bryan et al., 2013]. Protecting these areas requires an enhanced understanding of their morphodynamics.

Beyond small-scale morphological patterns of sandy coastlines (e.g., beach cusps and rip channels), evolving over daily to weekly timescales [Almar et al., 2008; Gallop et al., 2011; Castelle and Coco, 2012; Stokes et al., 2015], the morphology of embayed beaches also vary at the scale of the embayment $(\mathrm{O}(1 \mathrm{~km}))$. Related patterns develop over monthly to interannual timescales [Ojeda et al., 2011; Daly et al., 2015] and dominate beach behavior [Clarke and Eliot, 1982; Short and Trembanis, 2004; Ojeda et al., 2011; Loureiro et al., 2012; Turki et al., 2013a]. They typically account for the cross-shore migration and the rotation of the beach shoreline and nearshore sandbars [Ojeda and Guillén, 2008; Ojeda et al., 2011; van de Lageweg et al., 2013], as well as variations of their curvature [Loureiro et al., 2012; Ratliff and Murray, 2014].

Waves and flow circulations are drivers of embayed beach morphodynamics that are strongly controlled by the local geological setting (e.g., the extent and separation of the headlands that enclose the beach) [Short, 1999; Castelle and Coco, 2012; Daly et al., 2014]. This aspect is reflected in the embayed beach classification proposed by Castelle and Coco [2012], based on the ratio of embayment length to time-averaged surfzone width $\delta$. For low values $(\delta<6)$, the geological setting dominates (e.g., high shoreline curvature and one central rip).
O2017. American Geophysical Union. All Rights Reserved. 
On the contrary, high values relate to long embayments where beaches exhibit typical open beach topographies with six or more rip channels. The present paper focuses on such a low-curvature embayed beach that in addition features a single nearshore sandbar.

Cross-shore migrations of the shoreline and nearshore sandbar reflect transitions toward more dissipative or more reflective states depending on the incident wave conditions [van Maanen et al., 2008; Ojeda and Guillén, 2008; van de Lageweg et al., 2013]. Recently, semiempirical models, based on a limited number of key primary processes, have been developed to explain and forecast the migration of the shoreline [Yates et al., 2009; Davidson et al., 2010, 2013; Splinter et al., 2014; Jara et al., 2015] and the nearshore sandbar [Plant et al., 1999, 2006; Splinter et al., 2011; Blossier et al., 2016]. In essence, this type of migration models defines a time-varying equilibrium location of the shoreline (or barline) and a migration intensity that depends on the incoming wave energy.

Rotation results from a contrasting evolution of the beach profile at the extremities of the embayment related to different erosion or accretion rates. Shoreline rotation has been observed in embayments characterized by large $\delta$ values (La Barceloneta (Spain), $\delta=24$ [Ojeda and Guillén, 2008; Turki et al., 2013b]; Collaroy-Narrabeen (Australia), $\delta=33$ [Harley et al., 2011]; and Tairua [van de Lageweg et al., 2013], which has a $\delta=31$ ). A relation between shoreline rotation and alongshore sediment transport was shown by Clarke and Eliot [1982] and Turki et al. [2013a], using principal component analyses (PCAs) on upper beach sediment volumes and shoreline planform shapes, respectively. Castelle and Coco [2012] confirmed the role of alongshore transport at embayed beaches of intermediate lengths (1 to $4 \mathrm{~km})$. However, Harley et al. [2011, 2015] showed that this concept may not always explain the rotation. Instead, varying cross-shore adaptations of the beach profile along the embayment can be related to alongshore gradients of wave energy, regardless of alongshore transport mechanisms. Blossier et al. [2016] showed that such gradient can also induce the rotation of nearshore sandbars at the embayment scale.

Cross-shore migrations and rotations of the shoreline and barline of a beach are processes that are rarely considered together. Research concerning shoreline and barline coupling has focused mainly on medium-sized morphological features such as rip channels $(\mathrm{O}(100 \mathrm{~m})$ ) [Coco et al., 2005; Ruessink et al., 2007; Castelle et al., 2010a, 2010b; van de Lageweg et al., 2013]. On a larger scale, at a double-barred embayed beach, Price and Ruessink [2011] showed that the state of the intertidal bar was influenced by the state of the subtidal bar. However, these studies did not assess if embayment-wide patterns such as cross-shore migrations, rotations, or changes of curvature, which dominate the beach variability at the scale of the embayment, are coupled. Early work has shown that shoreline and sandbars tend to migrate in opposite directions when the beach morphology evolves toward a reflective or dissipative state [e.g., Wright and Short, 1984]. More recently, Ojeda et al. [2011] and van de Lageweg et al. [2013] reported qualititatively that the shoreline and barline of an embayed beach tend to rotate in the same direction, but they also observed events showing opposite rotations. The connection between sandbar and shoreline has only been quantitatively explored through the study of single profiles [e.g., Roelvink and Brøker, 1993; van Rijn et al., 2003; Grasso et al., 2009; Ludka et al., 2015]. Therefore, the context of the larger-scale embayment-wide coupling remains largely unexplored, even though these spatial scales are critical to understanding beach erosion and recovery.

Therefore, in this paper, we determine the degree to which large-scale shore and bar morphodynamics are coupled and under what forcing conditions such coupling occurs. This is achieved by isolating the dominant morphodynamic patterns of the shoreline and barline considered as one dynamic system using PCA. Our analysis does not presuppose any hypothesis about the shoreline and barline behaviors, but according to the literature, we expect them to account for cross-shore migration, rotation, and change of curvature, and we will assess to which extent this is the case. More fundamentally, the resulting PCA patterns will reveal whether shoreline and barline movements occur at the same time or not. If they do move together, in which case this provides evidence of coupling, we will assess whether this movement is in the same or opposite direction. Otherwise, if the movement does not occur in the shoreline and sandbar together, patterns will describe independent behaviors of the shoreline or barline. We will therefore discriminate between simultaneous patterns (coupled behaviors) and nonsimultaneous patterns (independent behaviors). After this identification, the potential environmental drivers of these simultaneous and nonsimultaneous patterns will be assessed.

We undertake our analysis at Tairua Beach, a typical example of a single-barred embayed beach located in the north island of New Zealand. Seven years of shoreline and barline positions derived from video imagery data, previously presented in van de Lageweg et al. [2013], are studied. To characterize dynamic patterns, this study 
introduces a PCA method that has not been used in beach morphology studies, which allows for the combined decomposition of the shoreline and barline dynamics into coupled modes that describe their simultaneous and nonsimultaneous behaviors. To support the interpretation of these modes, standard PCAs are performed separately on the shoreline and barline data sets. Finally, we show that four equilibrium models for shoreline and barline migration and rotation can partially simulate the observed modes, enabling to associate the corresponding beach behaviors with the external wave conditions driving the models.

\section{Study Area and External Conditions}

\subsection{Geological Characteristics}

Tairua Beach is located at the east coast of the New Zealand north island, in the Coromandel peninsula (Figure 1). This peninsula is a region of ancient volcanic activity [Booden et al., 2012], accounting for its rugged coastal topography. Along its eastern coastline, rocky shores are intersected by numerous embayed beaches resulting from local sediment supply by rivers or bypassing effects [Hart and Bryan, 2008].

Tairua Beach is $1.2 \mathrm{~km}$ long and enclosed between two headlands extending approximately $600 \mathrm{~m}$ seaward from the dune foot - Pumpkin Hill at the north and Paku Hill at the south. The beach is partly sheltered from waves by Shoe Island, located $3 \mathrm{~km}$ east of Paku Hill and extending over $1 \mathrm{~km}$ from south to north.

Tairua Beach is mainly facing easterly and northeasterly long-traveling swell and storm waves. Far offshore, significant wave heights are $1.4 \mathrm{~m}$ on average and can reach $6 \mathrm{~m}$ during storms [Smith and Bryan, 2007]. The beach, constituted of medium to coarse sand ( $d_{50}$ between $300 \mu \mathrm{m}$ and $600 \mu \mathrm{m}$ according to Smith and Bryan [2007], van Maanen et al. [2008], and our own surveys), is located in a microtidal environment with a tidal range varying between 1.2 and $2 \mathrm{~m}$. Tairua features a single distinct shore-parallel sandbar and shows intermediate beach states mostly ranging from longshore bar and trough to transverse bar and rips [Bogle et al., 2001; van Maanen et al., 2008]. The lower shoreface slope is approximately 0.02 [Blossier et al., 2016], whereas the upper beach slope is rather steep $(\approx 0.2$ [Smith and Bryan, 2007]). Transient intertidal bars can appear along Tairua Beach shoreline, but they are not taken into account in the present paper.

The beach exhibits regular successive progradation and retreat events as well as shoreline and barline rotations [van Maanen et al., 2008; Bryan et al., 2013; van de Lageweg et al., 2013; Blossier et al., 2016]. Smaller-scale morphological features have also been observed such as beach cusps [Almar et al., 2008] and rip channels [Gallop et al., 2011].

\subsection{Wave Data in the Bay of Plenty}

There is no permanent wave buoy or other instrument deployed in the vicinity of Tairua Beach, but one buoy has been collecting deep water wave data since 2003, $90 \mathrm{~km}$ south of Tairua. It is maintained by the Bay of Plenty Regional Council (BoPRC) and provides continuous bulk wave spectrum parameters every hour since then (B, Figure $1 b)$.

To obtain the wave characteristics at Tairua Beach, a regional wave model was set up in SWAN [Booij et al., 1999] and applied for the Bay of Plenty, nested within the global WaveWatch III hindcast model from the National Oceanic and Atmospheric Administration (NOAA). The main surface driver of the SWAN model is the new Climate Forecast System Reanalysis data set of hourly $0.5^{\circ}$ spatial resolution winds from the National Centers for Environmental Prediction. The model was calibrated using the data of the BoPRC buoy $\left(R^{2}\right.$ between 0.7 and 0.9, Relative Mean Absolute Error, RMAE, below 0.1 for the significant wave height $H_{s}$ and mean wave period $T_{m}, R^{2}=0.5$ for the wave angle of incidence, increasing to 0.7 for $H_{s}>0.7 \mathrm{~m}$ ).

To further validate the model in the domain of interest, observations were collected during three 6 week periods in March to April, August to September, and October to November 2011 at three different locations in the vicinity of Tairua Beach, at $8 \mathrm{~m}$ depth. S4 instruments (InterOcean) measured pressure and horizontal velocities (PUV) at the extremities of Tairua Beach and immediately south of Paku Hill (S4_N, S4_S, and S4_P, Figure $1 \mathrm{~d}$ ). Comparing the model with observations, $R^{2}$ is between 0.5 and 0.8 for $H_{s}$, with a root-mean-square error, RMSE, between 0.1 and 0.2. $R^{2}$ is below 0.5 for the wave angle of incidence. However, $R^{2}$ falls between 0.4 and 0.7 for the wave energy $E_{y}$ available for alongshore sediment transport $\left(E_{y}=E \cos (\theta) \sin (\theta)\right.$, with $E$ the wave energy [Komar and Inman, 1970]). This improvement is potentially due to the fact that $E_{y}$ minimizes the role of the smallest waves for which the angle of incidence is not simulated as well as for higher waves. $H_{s}$ and $E_{y}$ at Tairua Beach are presented in Figure 2. 


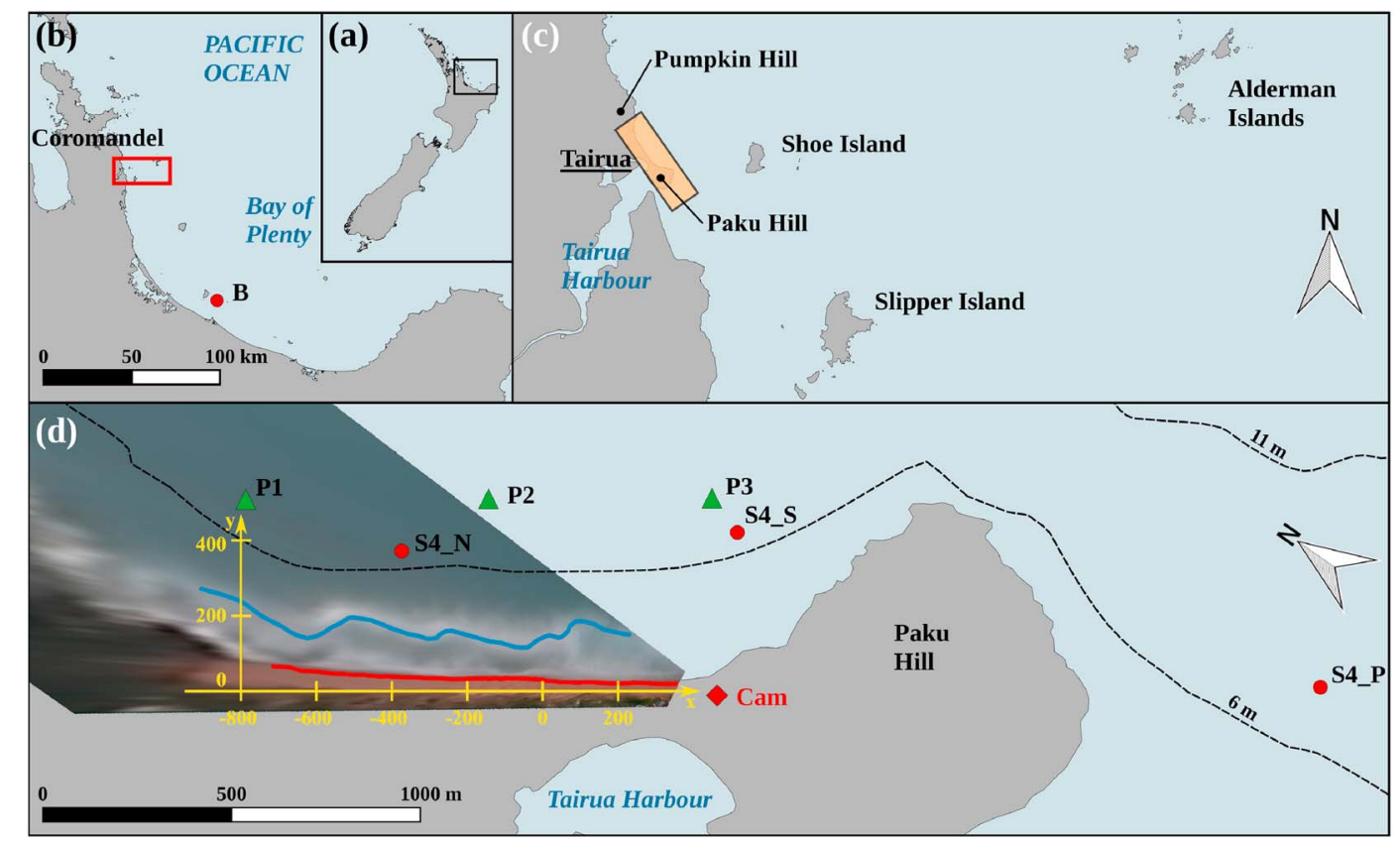

Figure 1. Location of Tairua (c) on the Coromandel peninsula (b) in the north island of (a) New Zealand. The yellow rectangle in Figure $1 \mathrm{c}$ shows the area of study which is represented rotated and in detail in Figure $1 \mathrm{~d}$. Red dot $B$ in Figure $1 \mathrm{~b}$ indicates the BoPRC wave buoy location. (d) Red dots S4_N, S4_S, and S4_P show the locations of the S4 used to validate the wave model. Example of extracted barline (27 June 2003, blue) and shoreline (25 June 2003, red) are depicted in Figure 1d over a georectified low tide image taken on 27 June 2003 and the local reference frame (yellow axes). Dashed lines indicate the 6 and $11 \mathrm{~m}$ depth contour lines compared to msl.

\subsection{Shoreline and Barline Data}

A video camera was installed in 1998 at Tairua Beach (Cam-Era network, National Institute for Water and Atmospheric Research, NIWA, Figure 1d), approximately $50 \mathrm{~m}$ above mean sea level (msl). Seven years of daylight hourly time exposure (timex) images (600 images averaged over $15 \mathrm{~min}$ ) are used in the present study, from 1999 to 2005.
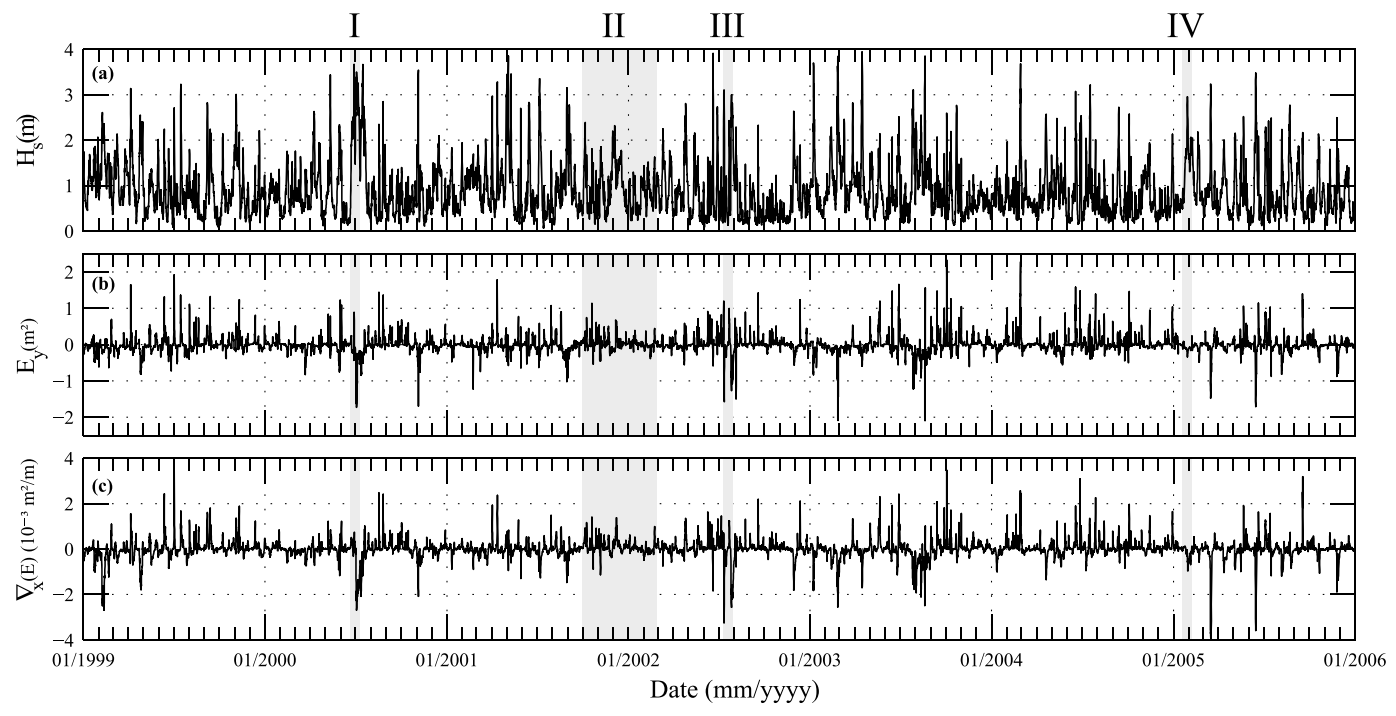

Figure 2. Significant (a) wave height $H_{s}$ (b) wave energy available for alongshore sediment transport $E_{y}$, and (c) alongshore wave energy gradient $\nabla_{x}(E)$ modeled at Tairua Beach for the study period $\left(E_{y}>0\right.$ relates to southward directed transport). Gray areas represent Events I, II, III, and IV. 
Shoreline and barline cross-shore positions have been extracted from the georectified timex images in van de Lageweg et al. [2013]. In agreement with Plant et al. [2007], shoreline elevations $\eta_{s}$ required for the georectification included the tidal level (NIWA numerical model [Walters et al., 2001]), and a wave runup correction [Bowen et al., 1968]. Images corresponding to a runup above $1.5 \mathrm{~m}$ were discarded. Below $1.5 \mathrm{~m}$, computed runup values agree with those computed following the more recent work of Stockdon et al. [2006] (maximum difference of $20 \mathrm{~cm}$ in the vertical, creating a shoreline difference of $1 \mathrm{~m}$ in the horizontal which is small compared to the patterns we are studying (see error discussion below)). To limit the influence of the tides on the runup, only high tide images were selected (tidal level between 0.2 and $0.6 \mathrm{~m}$ above msl) following Guedes et al. [2011]. In the present study, a shoreline is defined as the contour line located $0.9 \mathrm{~m}$ above Mean High Water Neap tidal level, i.e., $1.5 \mathrm{~m}$ above $\mathrm{msl}$. Using a tolerance of $25 \mathrm{~cm}\left(1.25 \mathrm{~m}<\eta_{\mathrm{s}}<1.75 \mathrm{~m}\right.$ above $\left.\mathrm{msl}\right), 1272$ shorelines are selected, resulting in a shoreline reading every 2 days on average. Barlines are extracted at the location of wave breaking, observed as white bands on the timex images. Only low tide images are used when the wave breaking needed to detect barlines was maximized (tidal levels falling between -1 and $-0.5 \mathrm{~m}$ ), resulting in 739 lines, i.e., a barline reading every 3.5 days on average. Shoreline and barline data sets are extracted in the same local reference frame (Figure 1d). A weekly moving average is applied to the data sets to filter out the noise introduced by the digitization and by small potential errors in the water level assessment. To allow for combined analysis, the averaged data sets are linearly interpolated over a 12-hourly time frame, resulting in signals $S(x, t)$ (shorelines) and $B(x, t)$ (barlines) presented in Figures $3 \mathrm{a}$ and $3 \mathrm{~b}$. In this figure, brown relates to more accreted beach states (accreted shoreline, nearshore barline location) while blue relates to more eroded states (eroded shoreline, offshore barline location).

At intermediate scales, rip channels (which cause undulations in the shoreline and barline) emerge, grow, and disappear along the shoreline (e.g., from December 2001 until July 2002) and the barline (e.g., from September 2000 until July 2002). These shoreline and barline undulations can exhibit a coupling reflected by identical wavelengths (e.g., January 2002), studied in van de Lageweg et al. [2013]. At the scale of the embayment, large migration (shoreward and seaward movement) and rotation events occur. To characterize these processes, a linear fit of each extracted shoreline and barline planform shape was performed to compute their alongshore-averaged cross-shore position $S_{0}$ and $B_{0}$, and their orientation $\alpha_{s}$ and $\alpha_{b}$ (subscripts $s$ and $b$ stand for shoreline and barline, respectively). They are presented in Figures $3 c-3 f$.

The shoreline and barline position and orientation errors were smaller than the patterns on which our study is based. The error for the shoreline position is evaluated by combining the influence of the cross-shore pixel footprint of the georectified images (maximum $0.7 \mathrm{~m}$ ), the standard deviation of the selected water levels after moving average $( \pm 0.07 \mathrm{~m}$ vertically that converts to $\pm 0.35 \mathrm{~m}$ horizontally considering an upper beach slope of 0.2$)$, the uncertainty in wave runup ( $+0.5 \mathrm{~m}$ and $-0.6 \mathrm{~m}$ vertically that converts to $+2.5 \mathrm{~m}$ and $-3 \mathrm{~m}$ horizontally [Bowen et al., 1968; Stockdon et al., 2006], and the possible influence of the tides [Guedes et al., 2011]). All together, the error falls between $+3.50 \mathrm{~m}$ and $-4 \mathrm{~m}$. The shoreline orientation error was induced by the pixel footprint and the uncertainty in runup (the absolute setup and the tidal level do not cause alongshore variations in error), i.e., $4.4 \times \pm 10^{-3}$ (all angles given in radians). With a video camera system similar to the system on Tairua Beach, van Enckevort and Ruessink [2001] and Ruessink et al. [2009] assessed the error in measuring nearshore sandbar locations. Their error was below $10 \mathrm{~m}$, before they would apply corrections for the influence of water level and wave height. This value of $10 \mathrm{~m}$ also agrees with the barline observations of Ribas et al. [2010]. Therefore, $10 \mathrm{~m}$, already used in Blossier et al. [2016], is also used in the present study to assess the influence of error in barline cross-shore position. This results in a barline orientation error of 0.017 . For the shoreline and barline orientations, as well as for the barline cross-shore position, the error is less than half the standard deviation of the signal (Table 1). As a result, most of the fluctuations of $\alpha_{s}, B_{0}$, and $\alpha_{b}$ are significant compared to the evaluated errors (Figures $3 d-3 f$ ). For the shoreline cross-shore position $S_{0}$, the error is between a half and one standard deviation, due to the uncertainty related to the runup extent. This does not alter the results of the present study (effect of errors on the results presented here are evaluated in more detail in Appendix A).

Four events have been selected to illustrate the beach behavior (Figure 3). Events I and IV show transitions from more reflective toward more dissipative states with strong erosion of the shoreline $(-15 \mathrm{~m}$ and $-10 \mathrm{~m})$ and large offshore migrations of the barline $(+50 \mathrm{~m}$ and $+60 \mathrm{~m})$. These migrations are accompanied by strong rotations of the barline in the clockwise direction, mainly due to larger offshore migration of the barline at the north compared to the south (Figure 3b). Shoreline rotation occurs in the same direction but is much smaller. Event II shows part of the transition of the beach toward more reflective states with progradation 

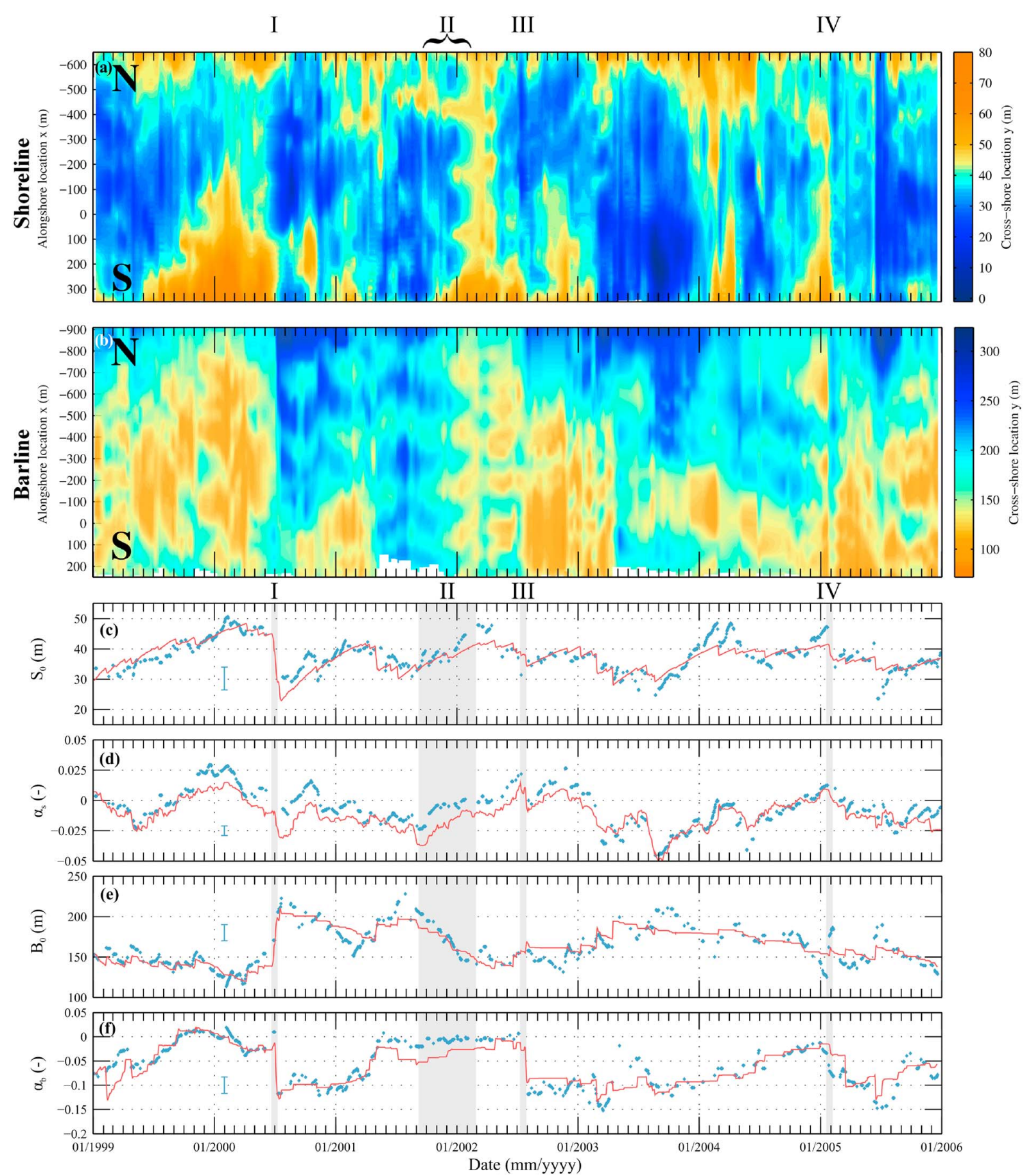

Figure 3. (a) Shoreline $S(x, t)(1.5 \mathrm{~m}$ above $\mathrm{msl})$ and (b) barline $B(x, t)$ planform shapes derived from 7 years of camera imagery at Tairua Beach [van de Lageweg et al., 2013]. Note that color scales are different for both panels. Observations (blue dots) and semiempirical models results (red lines) for (c) alongshore-averaged shoreline cross-shore position $S_{0}$, (d) shoreline orientation $\alpha_{s}$, (e) barline cross-shore position $B_{0}$ (e), and (f) barline orientation $\alpha_{b}$. Gray areas represent Events I, $\mathrm{II}, \mathrm{III}$, and IV. Error bars represent the measurement errors mentioned in the text. 


\begin{tabular}{|c|c|c|c|c|c|c|}
\hline Parameter & Min & Max & $\sigma$ & RMSE & $R^{2}$ & Bss \\
\hline$S_{0}$ & 24.7 & 50.5 & 5.3 & 3.2 & 0.67 & 0.64 \\
\hline$\alpha_{s}$ & -0.05 & 0.03 & 0.02 & 0.010 & 0.79 & 0.62 \\
\hline$B_{0}$ & 113.5 & 228.2 & 23.7 & 11.8 & 0.75 & 0.75 \\
\hline$\alpha_{b}$ & -0.15 & 0.02 & 0.05 & 0.022 & 0.77 & 0.77 \\
\hline
\end{tabular}

of the shoreline $(+15 \mathrm{~m})$ and shoreward migration of the barline $(-50 \mathrm{~m})$. During this accretionary sequence, the shoreline rotates in the counterclockwise direction (+0.025) and the barline orientation is nearly stable (note also the development of rip channels). In contrast with Events I, II, and IV, Event III exhibits very little migration of the shoreline and barline; however, large clockwise rotations are observed for the shoreline $(-0.025)$ and the barline $(-0.125)$.

Other large-scale morphodynamic processes can be observed such as the variability of the curvature of the shoreline and barline. In Figures $3 a$ and 3b, a large curvature can be characterized by a central area of the shoreline (or barline) that is located more seaward, or more shoreward, than its two extremities (e.g., June 1999 until June 2000 and February to April 2004 for the shoreline; e.g., June 1999 until June 2000 and May 2003 until January 2004 for the barline). Low curvature can be characterized by similar cross-shore positions of the extremities and central areas (e.g., February 1999, January 2002, and June 2005 for the shoreline; e.g., March 1999, February to June 2002, and January 2005 for the barline). These patterns can sometimes be hidden by medium-scale patterns such as undulations or superimposed large-scale patterns such as shoreline or barline obliquity observed after rotation events, which can make them difficult to identify.

\section{Analysis Methodology}

\subsection{Principal Component Analyses}

PCA has been widely used to characterize dominant modes of dynamic systems where multiple patterns occur together such as Tairua Beach. Examples of use include beach profiles [Winant et al., 1975; Wijnberg and Terwindt, 1995; Karunarathna et al., 2012; Ludka et al., 2015; Kuriyama and Yanagishima, 2016], shoreline planforms [Miller and Dean, 2007a; Hansen and Barnard, 2010; Harley et al., 2011; Turki et al., 2013b], and alongshore bar patterns [Lippmann and Holman, 1990; Dai et al., 2008]. In this paper, PCA is used to reveal the simultaneity of the shoreline and barline dynamics at Tairua Beach by identifying coupled shoreline and barline patterns. PCA is well-suited for this purpose since it can extract such patterns without assuming anything about their nature a priori.

A PCA decomposes a two-dimensional signal into two separate sets of orthogonal vectors. A pair of equally ranked vectors in each set constitute a mode (i.e., a dynamic pattern). In the usual PCA approach in climate and morphodynamics studies, one signal dimension is often temporal, while the other is usually physical (e.g., the alongshore position). Short and Trembanis [2004], Alvarez-Ellacuria et al. [2011], Turki et al. [2013a], and Harley et al. [2011] focused on such 2-D signals (shoreline cross position defined as a function of time and alongshore position). They extracted a small number of modes (usually 2), which together often explained more than $80 \%$ of the shoreline variability. In this paper, this approach (hereafter referred to as Method 1, Figure 4) leads to two independent decompositions for the demeaned and normalized shoreline and barline signals, $\hat{S}\left(x_{s}, t\right)$ and $\hat{B}\left(x_{b}, t\right)$, respectively:

$$
\begin{aligned}
& \hat{S}\left(x_{s}, t\right)=\sum_{i} \lambda_{s, i} c_{s, i}(t) e_{s, i}\left(x_{s}\right), \\
& \hat{B}\left(x_{b}, t\right)=\sum_{i} \lambda_{b, i} c_{b, i}(t) e_{b, i}\left(x_{b}\right)
\end{aligned}
$$

with $\lambda$ scalars with no unit ( $\hat{S}$ and $\hat{B}$ are normalized), $c$ temporal vectors, and e spatial vectors. Subscript $i$ refers to the mode rank, and subscript $s(b)$ refers to shoreline (barline). For instance, the pair of equally ranked vectors $c_{s, i}$ and $e_{s, i}$ constitutes mode $M_{s, i}$ and describes a dynamic pattern. The contribution of mode $M_{s, i}$ and its associated pattern to the variance of $\hat{S}\left(x_{s}, t\right)$ is expressed by $\lambda_{s, i^{\prime}}^{2}$ since modes are orthogonal and the sum of $\lambda_{s, i}^{2}$ is 1 (due to the normalization). This method extracts the dominant patterns of the shoreline and barline 


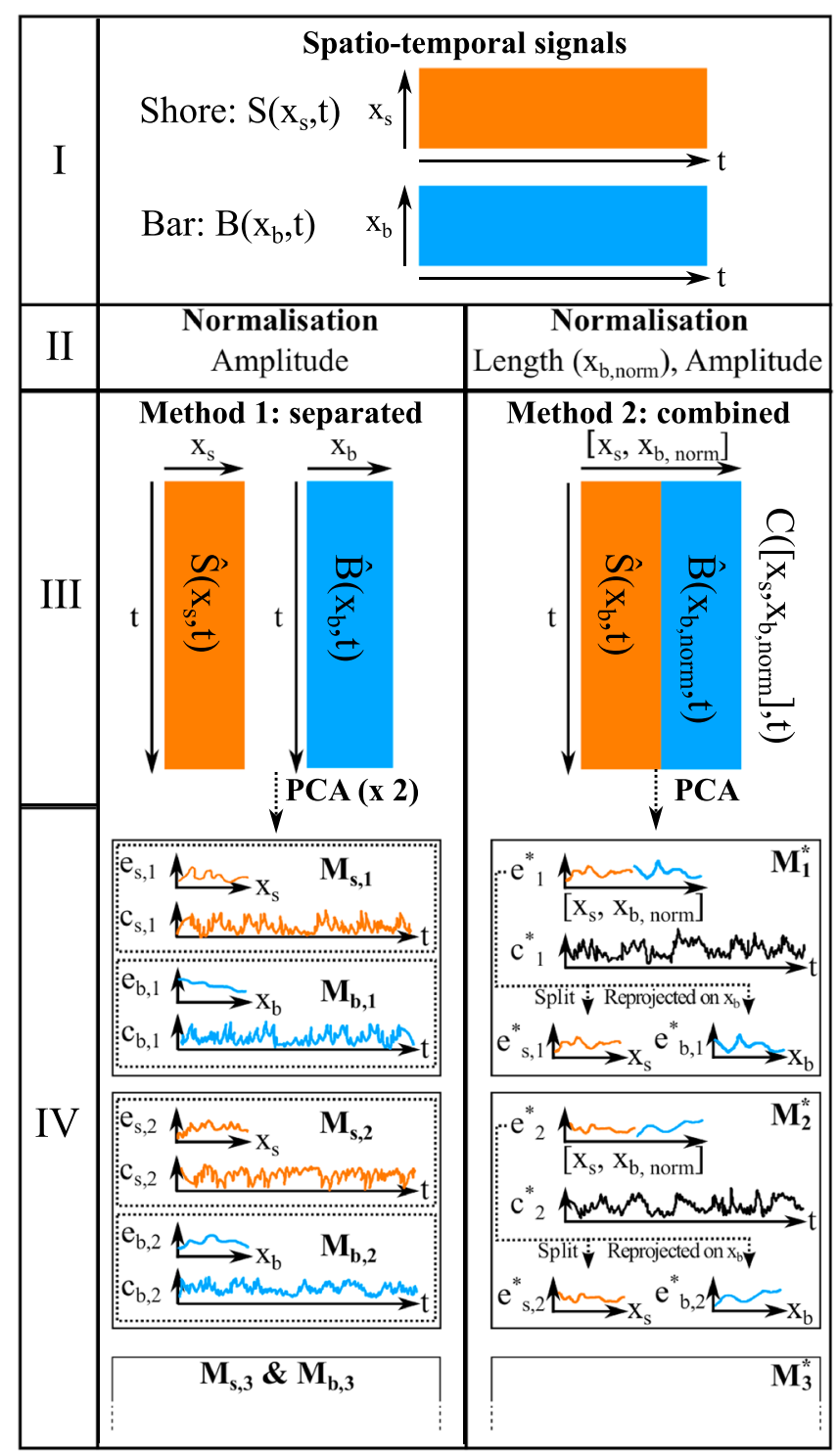

Figure 4. Description of the two methods used in the present paper to perform PCA on the shoreline and barline signals. I: shoreline and barline signals as depicted in Figures 3a and 3b. II: normalization of the signals. III: stacking of the shoreline and barline arrays for Method 2. IV: Extraction of the modes with their spatial vectors and associated time functions. Method 1: the shoreline and barline are decomposed into separated modes $M_{s, i}$ and $M_{b, i}$, each with their spatial vector $\left(e_{s, i}\right.$ and $\left.e_{b, i}\right)$ and time function $\left(c_{s, i}\right.$ and $\left.c_{b, i}\right)$. Method 2: modes are extracted for the stacked \{shoreline-barline\} signal. For each mode $M_{i}^{*}$, the spatial vector $e_{i}^{*}$ and time function $c_{i}^{*}$ account for both the shoreline and barline. Vector $e_{i}^{*}$ is split into two parts related to the shoreline $\left(e_{s, i}^{*}\right)$ and to the barline $\left(e_{b, i}^{*}\right)$ for readability.

behaviors separately without considering their interrelation. In this study, the significance (95\%) level of each PCA mode is established using the rule of thumb of North et al. [1982], and a Monte Carlo approach using surrogate red noise spectra. Autocorrelation in signals is taken into account following Zwiers and von Storch [1995]. More details can be found in Appendix B.

However, Method 1 does not allow for the PCA to identify simultaneous and nonsimultaneous shoreline and barline behaviors. Therefore, a second approach (hereafter referred to as Method 2, Figure 4) is proposed, in which the PCA is applied to a 2-D signal that accounts for the variability of both the shoreline and barline. For this, $\hat{B}\left(x_{b}, t\right)$ is further normalized so that it can be expressed in the same scale of variation as $\hat{S}\left(x_{s}, t\right)$, giving $\hat{B}\left(x_{b, \text { norm }}, t\right)$, where $x_{b, \text { norm }}$ is a spatial vector of the same size as $x_{s}$ (Figure 4 , II). This ensures that $\hat{S}\left(x_{s}, t\right)$ and $\hat{B}\left(x_{b, \text { norm }}, t\right)$ contain identical amounts of variability. This is critical since without complete normalization, the PCA decomposition would be controlled by the variance of the barline, which is an order of magnitude above 
the variance of the shoreline. Then, $\hat{S}\left(x_{s}, t\right)$ and $\hat{B}\left(x_{b, \text { norm }}, t\right)$ are stacked along the spatial dimension, resulting in one signal $C\left(\left[x_{s}, x_{b, \text { norm }}\right], t\right)$ (Figure 4 , III). This method of stacking is commonly used in applying PCA to 3-D (two spatial, one time) measurements such as atmospheric pressure [Hannachi et al., 2007]. Finally, a standard PCA is applied on $C$ :

$$
\begin{gathered}
C\left(\left[x_{s}, x_{b, \text { norm }}\right], t\right)=\sum_{i} \lambda_{i}^{*} c_{i}^{*}(t) e_{i}^{*}\left(\left[x_{s}, x_{b, \text { norm }}\right]\right), \\
e_{i}^{*}\left(\left[x_{s}, x_{b, \text { norm }}\right]\right)=\left[e_{s, i}^{*}\left(x_{s}\right), e_{b, i}^{*}\left(x_{b, \text { norm }}\right)\right]
\end{gathered}
$$

with superscript $*$ standing for this second method and [,] indicating stacked vectors or signals. The PCA outcome is therefore a set of stacked shoreline and barline vectors $e_{i}^{*}$ and a set of corresponding temporal vectors $c_{i}^{*}$ that constitute modes $M_{i}^{*}$ (Figure $4, \mathrm{IV}$ ). The stacked vectors $e_{i}^{*}$ are split into shoreline and barline shapes ( $e_{s, i}^{*}$ and $e_{b, i}^{*}$ respectively) to assist in interpretation and to allow comparison with the first method. In the following, $e_{b, i}^{*}\left(x_{b, n o r m}\right)$ is expressed on $x_{b}$ for easier comparison with $e_{b, i}$, with the same notation $e_{b, i}^{*}$. With this method, shoreline and barline vectors of same rank $i, e_{s, i^{\prime}}^{*}$ and $e_{b, i}^{*}$ correspond to the same mode $M_{i}^{*}$ and single temporal vector $c_{i}^{*}$ (Figure 4, IV). A key implication is that the temporal variations of the shoreline and barline shapes occur simultaneously.

This is not sufficient to conclude that the shoreline and barline behavior described by mode $M_{i}^{*}$ is simultaneous. For instance, an independent behavior of the shoreline could be captured by a mode $M_{i}^{*}$ in which the part describing the barline behavior is true but trivial. In other words, the shoreline part of the mode, $e_{s, i}^{*}$ and $c_{i}^{*}$, would explain a significant amount of the variability of the shoreline (above $5 \%$ ) while the barline part of the mode, $e_{b, i}^{*}$ and $c_{i}^{*}$, would be nonsignificant (below 5\%).

In the following, $M_{i}^{*}$ is defined as a simultaneous mode and therefore describes a simultaneous dynamic pattern of the shore and bar, if it explains more than $5 \%$ for both the shoreline and the barline variability. On the contrary, if the amount of variability explained by $M_{i}^{*}$ is above $5 \%$ for the shoreline only (or for the barline only), then $M_{i}^{*}$ describes a dynamic pattern of the shoreline only (or barline only) and is therefore named a nonsimultaneous mode.

\subsection{Identification of Drivers}

Different methods were used in the literature to relate dynamic patterns to external forcing conditions. For instance, Miller and Dean [2007b] and Harley et al. [2011] studied the correlations between PCA temporal vectors and external forcing conditions, while Larson et al. [2000] and Ruiz de Alegria-Arzaburu et al. [2010] used a linear statistical procedure, the Canonical Correlation Analysis. These methods assume that the temporal behavior of the extracted modes depends linearly on forcing conditions. However, it has been shown that the response of a beach to varying external conditions can be influenced by its present state [Miller and Dean, 2004; Yates et al., 2009; Sénéchal et al., 2015] and can be strongly nonlinear [Splinter et al., 2011; Blossier et al., 2016].

Therefore, in this paper, we use another approach. The two PCA methods applied to the data are also applied to the alongshore-averaged cross-shore position and orientation of Tairua Beach shoreline and barline, when simulated by four equilibrium models. Resulting model-based modes and vectors are marked with a tilde (e.g., $\tilde{M}_{i}^{*}, \tilde{e}_{s, i}$ ). If data-based modes (e.g., $M_{i}^{*}$ ) and model-based modes (e.g., $\tilde{M}_{i}^{*}$ ) are similar, then not only the models will explain some of the variance of the data-based modes induced by migration and rotation but these two processes will be found to be sufficient to explain the dominant behavior of Tairua Beach. In addition, the simple formulation of the equilibrium models will allow for a limited number of wave forcing parameters (e.g., wave height, period, and angle of incidence) to be associated with a large-scale dynamic pattern of the beach (potentially composed of mixed migration, rotation, and change of curvature of the shoreline and/or barline).

Short descriptions of the four semiempirical models used to simulate the alongshore-averaged cross-shore position and orientation of the shoreline and barline at Tairua Beach are given here, while details can be found in Appendix C.

The model of Yates et al. [2009], describing the shoreline alongshore-averaged cross-shore position $S_{0}$, is adapted by using only one free coefficient instead of different ones for shoreline accretion and erosion, and by allowing 
for a linear trend of $S_{0}$. This trend accounts for accretion or erosion processes that are not related to wave-induced cross-shore transport, similar to Davidson et al. [2013]. The model is

$$
\frac{\mathrm{d} \tilde{S}_{0}}{\mathrm{~d} t}=C_{s} \sqrt{E}\left(E-p_{s} \tilde{S}_{0}-p_{s} q_{s} t-r_{s}\right)+q_{s}
$$

where $C_{s}\left(m^{2} s^{-1}\right), p_{s}(m), q_{s}\left(m s^{-1}\right)$, and $r_{s}\left(m^{2}\right)$ are free constant coefficients of the model, $E\left(m^{2}\right)$ is the alongshore-averaged incident wave energy at time $t$, and $\tilde{S}_{0}(m)$ is the modeled $S_{0}$.

The second model relates the shoreline rotation rate to the amount of wave energy available for alongshore sediment transport [Komar and Inman, 1970], defining the equilibrium orientation of the shoreline as the normal to the wave angle of incidence $\theta$ [Turki et al., 2013b]. For small values of the shoreline orientation $\alpha_{s}$, the model formulation becomes:

$$
\frac{\mathrm{d} \tilde{\alpha}_{s}}{\mathrm{~d} t}=C_{\alpha_{s}} E\left[\sin (\theta) \cos (\theta)-\tilde{\alpha}_{s} \cos (2 \theta)\right],
$$

where $C_{\alpha_{s}}\left(m^{2} s^{-1}\right)$ is a free coefficient of the model and $\tilde{\alpha}_{s}(-)$ the modeled $\alpha_{s}$.

The barline parameters are modeled by semiempirical models developed and validated in Blossier et al. [2016]. The barline alongshore-averaged cross-shore position $B_{0}$ is described by

$$
\begin{gathered}
\frac{\mathrm{d} \tilde{B}_{0}}{\mathrm{~d} t}=C_{b} \sqrt{E}\left(E-\left(a_{b} \tilde{B}_{0}+b_{b}\right)\right) f_{b}\left(H_{s}, H_{b}\right), \\
f_{b}\left(H_{s}, H_{b}\right)=\min \left(\left[\frac{H_{s}}{H_{b}}\right]^{p}, 1\right)
\end{gathered}
$$

with $f_{b}(-)$ is a morphodynamic damping factor related to the morphodynamic activation of the bar and depending on the ratio of offshore significant wave height at $8 \mathrm{~m}$ depth $\left(H_{s}(m)\right)$ over the breaking wave height at the bar crest $\left(H_{b}(m)\right)$. Coefficient $p$ is equal to 8 , and $C_{b}\left(m^{2} s^{-1}\right), a_{b}(m)$, and $b_{b}\left(m^{2}\right)$ are free coefficients of the model. $\tilde{B}_{0}(m)$ is the modeled $B_{0}$.

The model of Blossier et al. [2016] suggests that the barline orientation $\alpha_{b}$ is controlled by the alongshore gradient of wave energy along the embayment $\nabla_{x}(E)$ (i.e., lower wave energy relates to the bar being closer to the shore and vice versa):

$$
\frac{\partial \tilde{\alpha}_{b}}{\partial t}=C_{\alpha_{b}}\left[\sqrt{E}\left(\nabla_{x}(E)-\delta_{b} a_{b}\left(\tilde{\alpha}_{b}-\alpha_{e q}\right)\right)+\frac{1}{2 \sqrt{E}} \nabla_{x}(E)\left(E-\left(a_{b} \tilde{B}_{0}+b_{b}\right)\right)\right] f_{b}\left(H_{s}, H_{b}\right)
$$

where $C_{\alpha_{b}}\left(m^{2} s^{-1}\right), \delta_{b}(-)$, and $\alpha_{e q}(-)$ are free parameters of the model and the values of $a_{b}$ and $b_{b}$ are determined during the calibration of the migration model (equation (7)). $\tilde{\alpha}_{b}(-)$ is the modeled $\alpha_{b}$.

The significant wave height and the incident wave angle required to run the models are extracted from the wave model output at point P2 (Figure 1d). To run the barline rotation model driven by the alongshore gradient of wave energy along the embayment (Figure 2c), significant wave heights are extracted at points P1 and P3 (Figure 1d).

The hindcasts of the four semiempirical models calibrated over the 7 year data set are presented in Figures $3 c-3 f$. The four semiempirical models simulate alongshore-averaged cross-shore positions and orientations of the shoreline and barline with fair to good skills. In each case, about $70 \%$ of the variance is explained (Table 1), and Brier skill scores fall between 0.6 and 0.8 (a fair to good fit, according to van Rijn et al. [2003]). The performance of the models is similar to the studies of Yates et al. [2009], Davidson et al. [2013] and Splinter et al. [2014] (shoreline migration), Plant et al. [1999] and Splinter et al. [2011] (barline migration), and Turki et al. [2013b] (shoreline rotation). Details on the calibration, validation, and performance are provided in Appendix C (shoreline) and Blossier et al. [2016] (barline).

Although a correlation study would be sufficient to evaluate the amount of variability of modes $M_{s, i}, M_{b, i}$, and $M_{i}^{*}$ that can be explained by the equilibrium models, applying the PCA to the models' outcomes will allow us to assess if the models are able to simulate the dynamic patterns described by $M_{s, i}, M_{b, i}$, and $M_{i}^{*}$, i.e., if they capture and describe the dominant scales of motion of the beach. To perform these PCAs, the modeled 
Method 1

Separated shore and bar modes
Method 2

Combined shore and bar modes

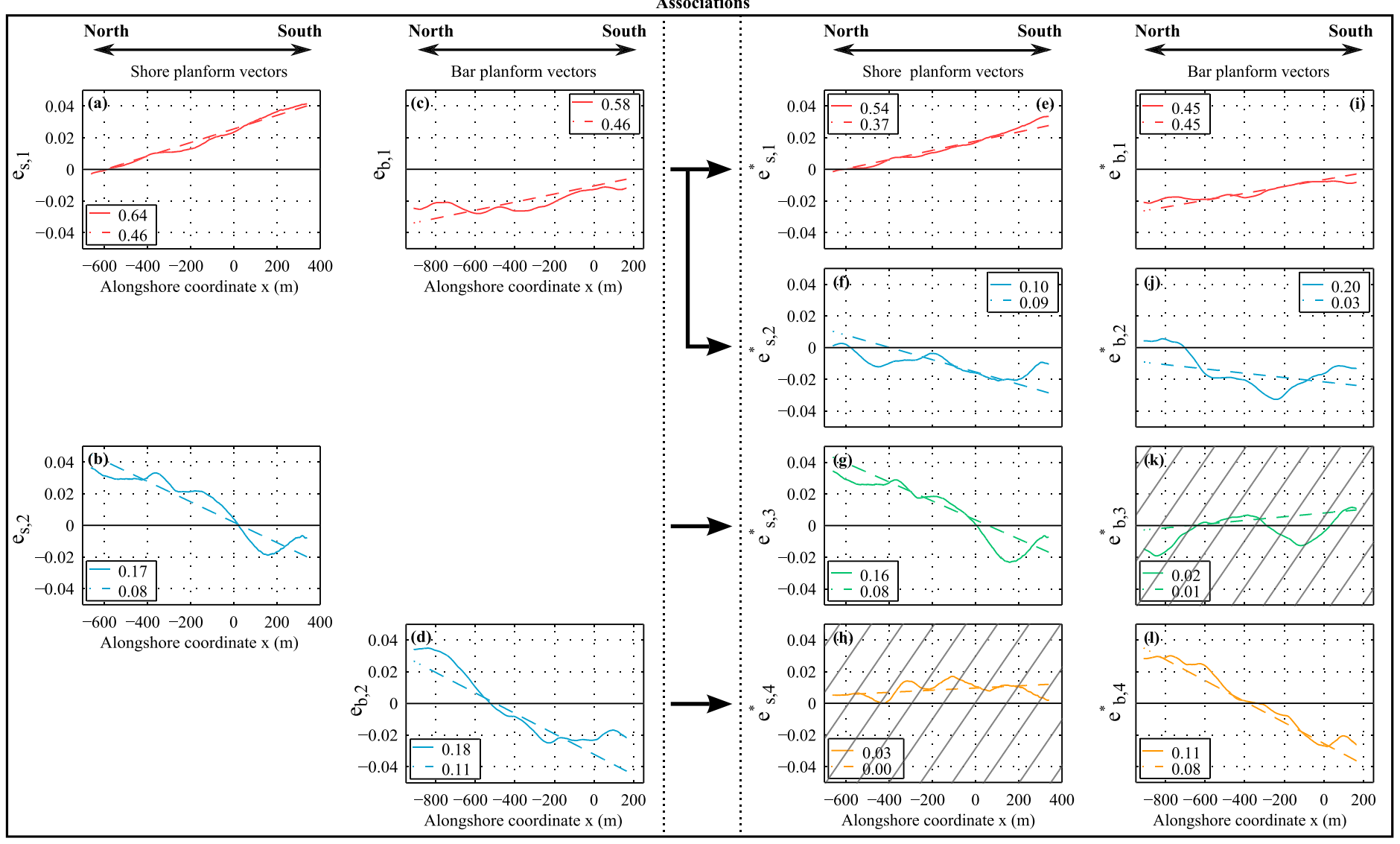

Figure 5. First and second spatial vectors computed for the shoreline ((a) $\left.e_{s, 1} ;(\mathrm{b}) e_{s, 2}\right)$ and the barline ((c) $e_{b, 1} ;$ (d) $\left.e_{b, 2}\right)$ using Method 1. Four first spatial vectors computed for the shoreline $\left((\mathrm{e}-\mathrm{h}) e_{s, i=1-4}^{*}\right)$ and the barline $\left((\mathrm{i}-\mathrm{l}) e_{b, i=1-4}^{*}\right)$ using Method 2 . Solid lines are related to observed data. Dashed lines are related to modeled data. The amount of shoreline and barline variability explained by the modes is given in the legends $\left(R^{2}\right)$. Spatial vectors associated with data-based modes explaining less than $5 \%$ of variability are hatched. Black arrows in the center indicate the associations of modes issued from Method 1 and Method 2 as described in the text.

shoreline and barline two-dimensional signals, $\tilde{S}(x, t)$ and $\tilde{B}(x, t)$, respectively, are reconstructed based on $\tilde{S}_{0}$ and $\tilde{\alpha}_{s}$ (shoreline), and $\tilde{B}_{0}$ and $\tilde{\alpha}_{b}$ (barline):

$$
\begin{aligned}
& \tilde{S}(x, t)=\tilde{S}_{0}(t)+\left(x-L_{s} / 2\right) \tilde{\alpha}_{s}(t), \\
& \tilde{B}(x, t)=\tilde{B}_{0}(t)+\left(x-L_{b} / 2\right) \tilde{\alpha}_{b}(t),
\end{aligned}
$$

with $L_{s}$ and $L_{b}$ the alongshore positions of the centers of the shoreline and barline observation areas, respectively.

\begin{tabular}{|c|c|c|c|c|c|c|c|c|c|c|c|c|c|c|c|c|}
\hline \multirow[b]{2}{*}{$i$} & \multicolumn{4}{|c|}{$M_{s, i}$} & \multicolumn{4}{|c|}{$M_{b, i}$} & \multicolumn{4}{|c|}{$M_{s, i}^{*}$} & \multicolumn{4}{|c|}{$M_{b, i}^{*}$} \\
\hline & $\overline{R^{2}}$ & $R_{M}^{2}$ & $R_{R}^{2}$ & $\overline{R_{U}^{2}}$ & $\overline{R^{2}}$ & $R_{M}^{2}$ & $R_{R}^{2}$ & $\overline{R_{U}^{2}}$ & $\overline{R^{2}}$ & $R_{M}^{2}$ & $R_{R}^{2}$ & $\overline{R_{U}^{2}}$ & $\overline{R^{2}}$ & $R_{M}^{2}$ & $R_{R}^{2}$ & $R_{U}^{2}$ \\
\hline 1 & 64 & 41 & 23 & - & 58 & 54 & 2 & 1 & 54 & 33 & 20 & - & 45 & 41 & 4 & - \\
\hline 2 & 17 & 6 & 10 & - & 18 & - & 15 & 2 & 10 & 8 & 1 & - & 20 & 12 & 3 & 4 \\
\hline 3 & 6 & - & - & 4 & 8 & - & 1 & 5 & 16 & 3 & 11 & - & 2 & - & - & - \\
\hline 4 & 4 & - & - & - & 5 & - & - & - & 3 & 2 & - & - & 11 & - & 10 & - \\
\hline
\end{tabular}

Table 2. Variance Explained by the Data-Based PCA Modes in Terms of Migration, Rotation, and Change of Curvature ${ }^{a}$

a For each mode, a cell contains successively $R^{2}$ values for the overall signal $\left(R^{2}\right)$, its migration $\left(R_{M}^{2}\right)$, its rotation $\left(R_{R}^{2}\right)$, and its change of curvature $\left(R_{U}^{2}\right)$ (with $R^{2} \geq R_{M}^{2}+R_{R}^{2}+R_{U}^{2}$ ). Values corresponding to modes presented in Figure 5 are shown in bold. 


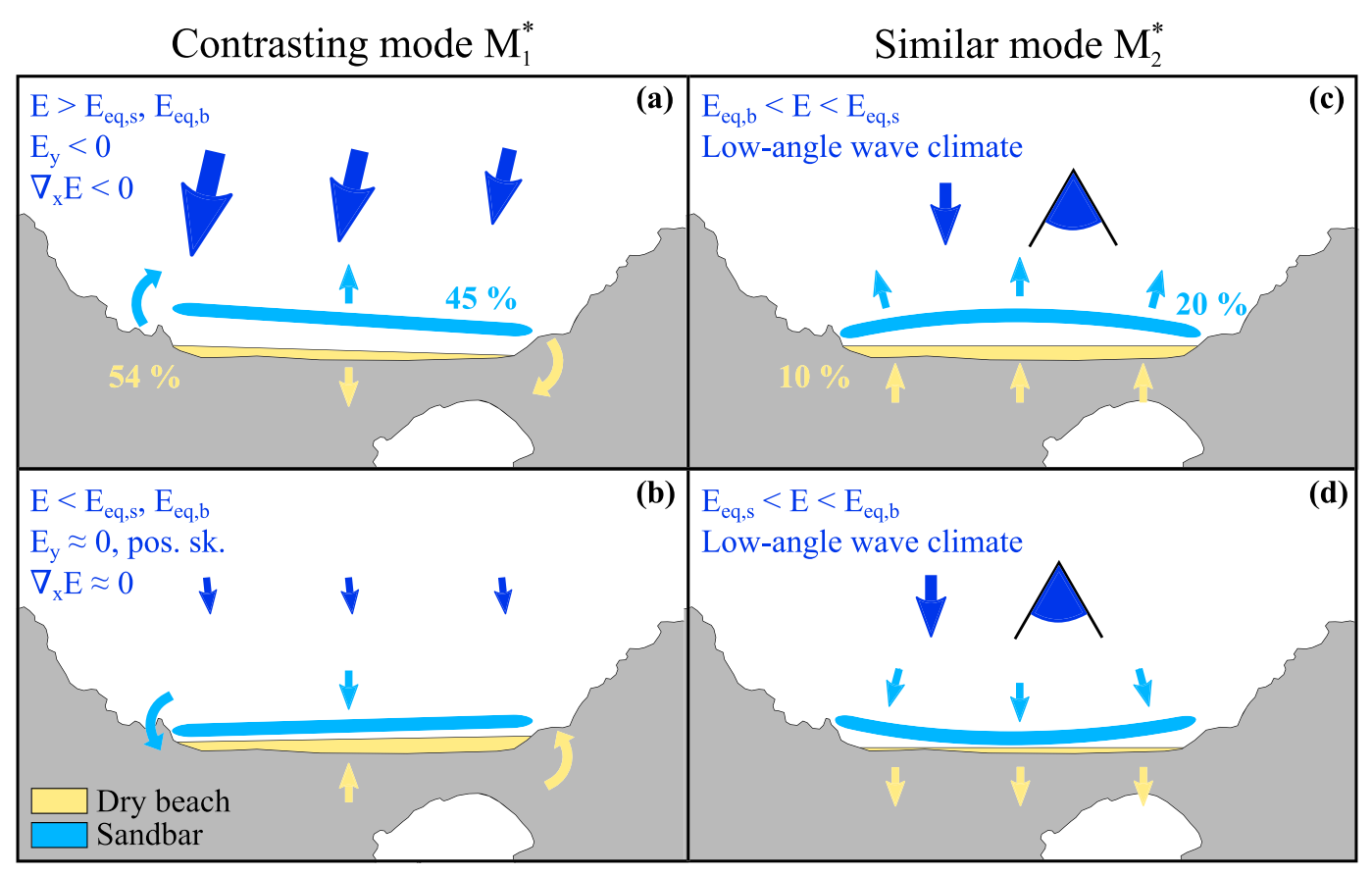

Figure 6. Schematic representations of dominant shore and bar behaviors observed at Tairua (simultaneous modes $M_{1}^{*}$ $\left((\mathrm{a}) c_{1}^{*}<0 ;(\mathrm{b}) c_{1}^{*}>0\right)$ and $M_{2}^{*}\left((\mathrm{c}) c_{2}^{*}<0 ;(\mathrm{d}) c_{2}^{*}>0\right)$ ). Percentages indicate the amount of variability explained by each mode for the shoreline (yellow) and barline (light blue). Arrows of the same colors indicate migration, rotation, and breathing patterns. Dark blue arrows and angular sectors relate to relevant wave climate properties described in each top left corner (pos. sk. = positive skewness).

\section{Results}

\subsection{Method 1: Separated Modes}

PCA was first applied independently to the 7 year shoreline and barline data sets following Method 1. Spatial vectors $e_{s, i}$ and $e_{b, i}$ of the first two modes $M_{s, i}$ and $M_{b, i}$ are presented in Figures $5 \mathrm{a}-5 \mathrm{~d}$. In addition, a decomposition of the amount of variability explained by each PCA mode $\left(R^{2}\right)$ in terms of migration $\left(R_{M}^{2}\right)$, rotation $\left(R_{R}^{2}\right)$, and change of curvature $\left(R_{U}^{2}\right)$ is given in Table 2 (details on the computation method are provided in Appendix D).

Modes $M_{s, 1}$ and $M_{s, 2}$ account for 64 and $17 \%$ of the shoreline variability, respectively (Figures $5 \mathrm{a}$ and $5 \mathrm{~b}$ ). They both account for shoreline movement that is a combination of migration and rotation (see $R_{M}^{2}$ and $R_{R}^{2}$ in Table 2). According to the dominant mode $M_{s, 1}$, the shoreline tends to rotate counterclockwise when it accretes (positive slope and positive alongshore-averaged value of $e_{s, 1}$ ), and vice versa (when the corresponding temporal vector, $c_{s, 1}$, becomes negative).

Modes $M_{b, 1}$ and $M_{b, 2}$ account for 58 and $18 \%$ of the barline variability, respectively (Figures $5 c$ and $5 \mathrm{~d}$ ). According to Table $2, M_{b, 1}$ describes barline movement that is dominated by migration and account for little rotation and change of curvature (the barline tends to rotate clockwise when it migrates seaward, with its center migrating further offshore, and vice versa). $M_{b, 2}$ describes a rotation which is well separated from barline migration (explained by $M_{b, 1}$ ) and accounts for curvature variations.

The results of the PCAs applied to $\tilde{S}(x, t)$ and $\tilde{B}(x, t)$ (shoreline and barline signals simulated by the equilibrium models) are also presented in Figure 5 (dashed lines). There is a general good agreement between the modeland data-based spatial vectors $\tilde{e}_{s, i}, e_{s, i}$ and $\tilde{e}_{b, i}, e_{b, i}$. Model-based modes necessarily describe less shoreline or barline variability (about 20 to 30\% less) as they do not account for spatial alongshore variability other than the overall shoreline or barline oblique orientation.

\subsection{Method 2: Combined Modes}

PCA is then performed on the stacked shoreline and barline signal (Method 2). In this case, spatial vectors $e_{s, i}^{*}$ and $e_{b, i}^{*}$ share the same temporal vectors $c_{i}^{*}$, so that modes $M_{i}^{*}$ characterize dynamic shoreline and barline patterns. The four first modes $M_{i=1-4}^{*}$ of the combined PCA analysis (Method 2) are presented in Figure 5. 


\begin{tabular}{|c|c|c|c|}
\hline Mode nb. & Shore & Bar & Shore \& Bar \\
\hline 1 & 0.85 & 0.89 & 0.90 \\
\hline 2 & 0.70 & 0.84 & 0.70 \\
\hline 3 & -0.02 & -0.09 & 0.70 \\
\hline 4 & -0.11 & 0.03 & 0.75 \\
\hline
\end{tabular}

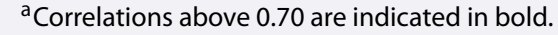

Subsequent modes explain little variability and are therefore ignored in the present study. Note that $R^{2}$ values in Figure 5, Method 2, do not refer to the variability of the stacked shore and bar signal but were recomputed separately for the shoreline and for the barline, after the PCA. They can therefore be directly compared to the values obtained for modes $M_{i=1-2}$ (Method 1).

$M_{1}^{*}$ and $M_{2}^{*}$ are simultaneous modes since they describe dynamic patterns that account for more than $10 \%$ of both the shoreline and barline variability. Vectors $e_{s, 1}^{*}$ and $e_{b, 1}^{*}$ show that $M_{1}^{*}$ describes the simultaneous progradation of the shoreline and shoreward migration of the barline both accompanied by counterclockwise rotation, and vice versa (Figures $5 e$ and $5 i$ ). In contrast to $M_{1}^{*}, e_{s, 2}^{*}$ and $e_{b, 2}^{*}$ show that $M_{2}^{*}$ describes the simultaneous retreat (or progradation) of both the shoreline and barline, accompanied by changes of barline curvature and minor rotations (slight clockwise rotation of shoreline and barline with beach retreat, and vice versa, Figures $5 f$ and $5 j$ ). A schematic representation of the beach behaviors described by $M_{1}^{*}$ and $M_{2}^{*}$ is proposed in Figure 6.

$M_{3}^{*}$ and $M_{4}^{*}$ are characterized by a nonnegligible contribution to the shoreline and the barline (more than $\left.10 \%\right)$, respectively, and a trivial contribution vice versa. For example, $M_{3}^{*}$ describes a dynamic pattern that is relevant for the shoreline (it explains $16 \%$ of its variability, Figure $5 \mathrm{~g}$ ). On the contrary, it describes a dynamic pattern for the barline that does not explain any of its variability ( $2 \%$ is below significant level, Figure $5 \mathrm{k}$ ). Therefore, $M_{3}^{*}$ and $M_{4}^{*}$ are nonsimultaneous modes. They account for independent shoreline and barline behaviors, essentially rotations (Table 2 ).

Model-based modes $\tilde{M}_{1}^{*}, \tilde{M}_{3}^{*}$, and $\tilde{M}_{4}^{*}$ show good agreement with data-based modes $M_{1}^{*}, M_{3}^{*}$, and $M_{4}^{*}$. In the two latter cases, good agreement is only relevant for the shoreline $\left(M_{3}^{*}\right)$ or the barline $\left(M_{4}^{*}\right)$. $M_{2}^{*}$ is only partially simulated by the models (poor fit between $e_{s, 2}^{*}$ and $\tilde{e}_{s, 2^{\prime}}^{*}$ and curved shapes of $e_{s, 2}^{*}$ and $e_{b, 2}^{*}$ that cannot be simulated by the models). However, the alongshore-averaged values of $e_{s, 2}^{*}$ and $\tilde{e}_{s, 2^{\prime}}^{*}$ and of $e_{b, 2}^{*}$ and $\tilde{e}_{b, 2}^{*}$ agree well, showing that the equilibrium models simulate part of the cross-shore migration described by $M_{2}^{*}$. Correlations above 0.7 reflect a fair correspondence between model- and data-based temporal vectors $c_{i=1-4}^{*}$ and $\tilde{c}_{i=1-4}^{*}$ (Table 3).

\section{Discussion}

\subsection{Simultaneity of Shore and Bar Behaviors}

5.1.1. Simultaneity

PCA using Method 1 showed that more than $60 \%$ of the variability of Tairua Beach is dominated by the shoreline and barline moving through combinations of migration and rotation $\left(M_{s, 1}\right.$ and $M_{b, 1}$, Table 2). In addition, $M_{s, 1}$ and $M_{b, 1}$ can immediately be compared with $M_{1}^{*}\left(e_{s, 1}^{*}\right.$ and $e_{b, 1}^{*}$ are similar to $e_{s, 1}$ and $e_{b, 1}$ (Figures $5 \mathrm{a}, 5 \mathrm{c}, 5 \mathrm{e}$, and $5 \mathrm{i})$, and the temporal vectors $c_{1}^{*}, c_{s, 1}$, and $c_{b, 1}$ agree well $\left(R^{2}>0.7\right.$, Figure $\left.7 \mathrm{a}\right)$ ). A decrease of approximately $10 \%$ of the variability explained by $M_{1}^{*}$ compared to $M_{s, 1}$ and $M_{b, 1}$ suggests that the missing amount could be explained by $M_{2}^{*}$ (shoreline: $10 \%$; barline: $20 \%$ ). The combinations of migration and rotation described by dominant modes $M_{s, 1}$ and $M_{b, 1}$ seem therefore to be described by two simultaneous modes $M_{1}^{*}$ and $M_{2}^{*}$, suggesting that the migration and rotation captured by these modes are coupled (Figures 5a, 5c, 5e, 5f, 5i, and $5 \mathrm{j})$.

Secondary behaviors are represented by modes $M_{s, 2}$ and $M_{b, 2}$ (Method 1, Figures $5 \mathrm{~b}$ and $5 \mathrm{~d}$ ). These modes account mainly for rotation $\left(R_{R}^{2}>10 \%\right.$, Table 2$)$, with $M_{s, 2}$ accounting also for minor migration and $M_{b, 2}$ for minor changes in curvature. The simultaneity or nonsimultaneity of these behaviors is revealed by Method 2 . Indeed, $M_{s, 2}$ can be compared with $M_{3}^{*}$ and $M_{b, 2}$ can be compared with $M_{4}^{*}$ (spatial vector $e_{s, 2}$ compares well 


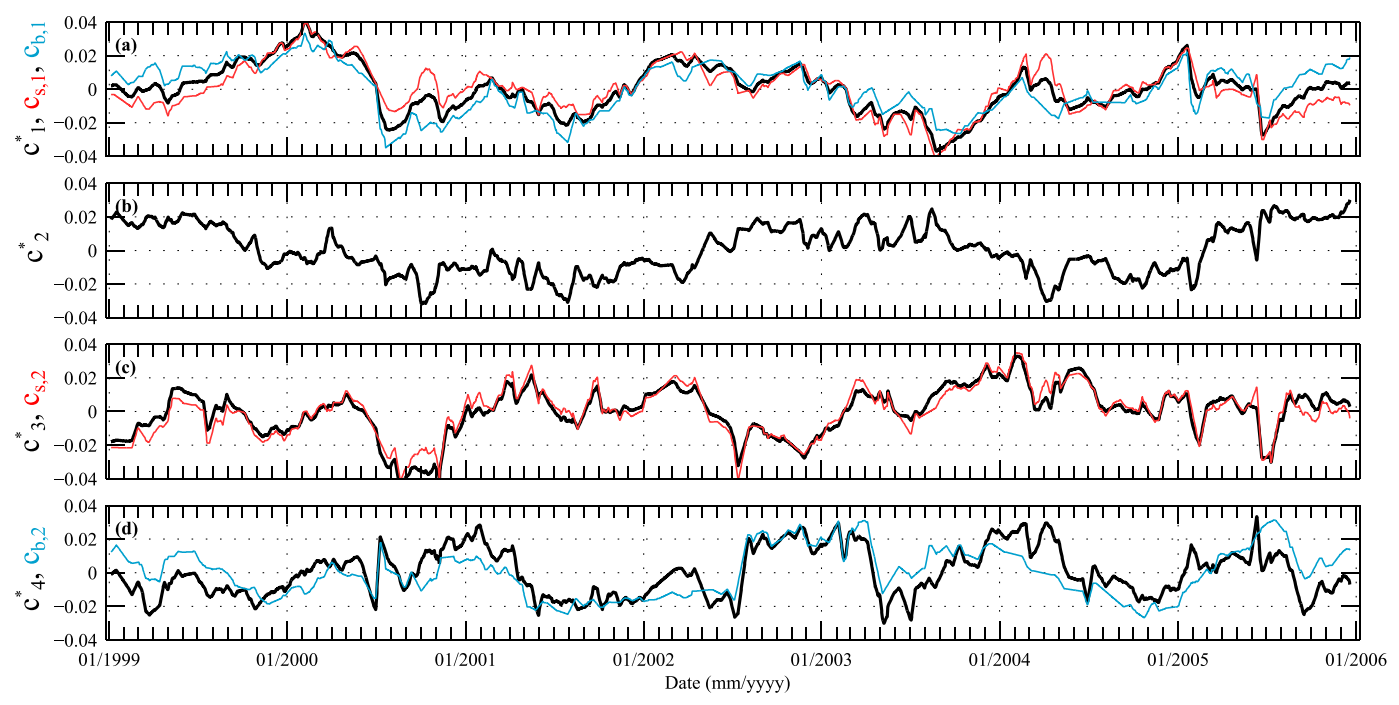

Figure 7. Main PCA modes temporal vectors. Black lines: temporal vectors corresponding to modes $M_{i=1-4}^{*}$ extracted with Method $2\left((\mathrm{a}) c_{1}^{*}\right.$, (b) $c_{2}^{*}$, (c) $c_{3}^{*}$, and (d) $\left.c_{4}^{*}\right)$. Red lines: Shoreline temporal vectors extracted with Method 1 ((a) $c s, 1$ and $(c) c s, 2)$. Blue line: Barline temporal vectors extracted with Method $1((a) c b, 1$ and $(d) c b, 2)$.

with $e_{s, 3}^{*}$, while temporal vectors $c_{s, 2}$ and $c_{3}^{*}$ correlate with $R^{2}=0.9 ; e_{b, 2}$ compares well with $e_{b, 4}^{*}$, while $c_{b, 2}$ and $c_{4}^{*}$ correlate with $R^{2}=0.5$ ). Therefore, we can conclude that secondary modes are nonsimultaneous and that the rotations of the shoreline and barline that they essentially capture are independent behaviors.

\subsubsection{Dominant Simultaneous Behaviors}

Unlike other beaches, the dominant behavior of Tairua beach includes migration and rotation of the shoreline and barline that do not occur independently. Indeed, the PCA analyses did not separate them either in the case of the shoreline $\left(M_{s, 1}\right)$, the barline $\left(M_{b, 1}\right)$ analyzed separately, or for both of them considered together $\left(M_{1}^{*}\right)$. $M_{1}^{*}$, that describes opposed migration directions of the shoreline and barline (e.g., the shoreline erodes while the bar moves seaward), accompanied by rotations in identical sense, is named contrasting mode hereafter. This mode can be associated with the transition of the beach toward more reflective or dissipative states and reflects the beach behaviors identified during Events I, II, and IV. The second simultaneous mode, $M_{2^{\prime}}^{*}$ mainly accounts for simultaneous cross-shore migrations, in identical direction, of the shoreline and barline. Therefore, $M_{2}^{*}$ is referred to as the similar mode hereafter.

$M_{2}^{*}$ also includes curvature variation of the barline ( $R_{U}^{2}$, Table 2). Ratliff and Murray [2014] studied the long-term behavior of embayed beach shorelines by modeling longshore sediment transport between headlands using the model of Ashton et al. [2001] and Ashton and Murray [2006]. They named a new dynamic mode breathing that relates to fluctuations in the curvature of the shoreline, which is not observed here. However, spatial vector $e_{b, 2}^{*}$ (Figure $5 \mathrm{j}$ ) of the similar mode $\left(M_{2}^{*}\right)$ shows a curved planform shape that could relate to such a breathing process of the barline. In addition, $M_{2}^{*}$ accounts for an overall retreat or progradation of the shoreline and barline system. Moreover, temporal vector $c_{2}^{*}$ exhibits interannual fluctuations with time periods of 3 to 4 years, which would agree with the characteristic time scales found by Ratliff and Murray [2014] for low-angle wave climate (Figure $7 \mathrm{~b}$ ). Such climate is found at Tairua, where only $8 \%$ of the 7 year simulated waves exceed an angle of incidence of $45^{\circ}$, which could explain the emergence of the similar mode (Figures 6c and 6d).

The contrasting and similar modes, $M_{1}^{*}$ and $M_{2}^{*}$, suggest that the dominant behavior of the beach could be associated with a strong coupling between the shoreline and barline, influencing each other at the scale of the embayment, as suggested in Harley et al. [2015]. By focusing on the simultaneous dynamic patterns of Tairua Beach, Method 2 was also able to extract a process that has similarities with the breathing of embayed beaches described by Ratliff and Murray [2014]. In Tairua, this process concerns the entire shore and bar system, exhibiting simultaneous, potentially coupled, shoreline and barline cross-shore migrations, and barline curvature variations. 


\subsection{Environmental Drivers}

It is not clear whether the coupling between the bar and shoreline (as evidenced by the simultaneous behavior) is caused by a direct effect of one on the other, or by them both responding independently (but simultaneously) to changes in wave forcing. In this section, the dependence on wave forcing is explored with simple equilibrium models and associated model-based PCA modes, as described in the methods.

5.2.1. Model-Based Modes

All aforementioned results and observations depend on the quality of the data set and the reliability of the PCA methods. In the following, the association of PCA modes with external forcing conditions rely on the reliability of the equilibrium models. Therefore, it is important to discuss the performance of these models in simulating the data-based modes $M_{s, i^{\prime}} M_{b, i^{\prime}}$ and $M_{i}^{*}$. Apart from $\tilde{e}_{s, 2^{\prime}}^{*} e_{s, 2}^{*}$ and $\tilde{e}_{b, 2^{\prime}}^{*} e_{b, 2^{\prime}}^{*}$ a good agreement was already found between the model- and data-based spatial vectors shapes. Apparent poor agreement between $\tilde{e}_{s, 2^{\prime}}^{*} e_{s, 2}^{*}$ and $\tilde{e}_{b, 2^{\prime}}^{*} e_{b, 2}^{*}$ should be interpreted in the context that their alongshore-averaged values agree well, showing that the equilibrium models simulate part of the cross-shore migration described by $M_{2}^{*}$. Good agreement between data- and model-based modes is confirmed by $R^{2}$ values above 0.7 found between their corresponding temporal vectors $\left(\tilde{c}_{s, i}, c_{s, i} ; \tilde{c}_{b, i}, c_{b, i} ; \tilde{c}_{i}^{*}, c_{i}^{*}\right.$, Table 3).

Such agreement shows explicitly that the equilibrium models are able to simulate the dynamic shoreline and barline patterns that dominate the beach behavior (as identified by the PCA). It also shows that the models simulate a ratio of migration and rotation of the shoreline and barline at the embayment-wide scale, which is similar to the observations (otherwise the model-based modes would be reshaped by, for instance, migration dominating over rotation, or shoreline dynamics dominating over barline dynamics). Therefore, we can proceed to use these models to explore the relationship of patterns to forcing condition.

\subsubsection{Migration}

Under adequate wave conditions, equilibrium models simulate the similar and contrasting modes. According to the migration models' formulations (equations (5) and (7)), the contrasting mode $M_{1}^{*}$ should be activated when the incident wave energy is higher than the shoreline and barline equilibrium energies $\left(E>E_{\text {eq,s }}\right.$ and $\left.E>E_{\mathrm{eq}, b}\right)$, inducing barline seaward migration and shoreline erosion. An incident energy lower than the equilibrium energies $\left(E<E_{\mathrm{eq}, \mathrm{s}}\right.$ and $E<E_{\mathrm{eq}, b}$ ) also drives the contrasting mode (landward barline migration associated with shoreline progradation). In the same manner, the similar mode $M_{2}^{*}$ describes an overall landward or seaward migration of both the shoreline and barline. This could occur not only due to a breathing process but also when the incident wave energy falls between the shore and bar equilibrium energies $\left(E_{\mathrm{eq}, \mathrm{s}}<E<E_{\mathrm{eq}, b}\right)$.

These relations between modes and equilibrium wave energies are reflected by the 7 year distribution of incident wave energy above, below, or in between $E_{\mathrm{eq}, s}$ and $E_{\mathrm{eq}, b}$. Time series of equilibrium and incident wave energy are presented in Figure 8 . In total, $80 \%$ of the overall incident wave energy at Tairua Beach is likely to drive the contrasting mode $90 \%$ of the time $\left(E>E_{\text {eq }, 5}\right.$ and $E>E_{\text {eq, } b}$ occur $7 \%$ of the time, accounting for $35 \%$ of the overall wave energy; $E<E_{\mathrm{eq}, \mathrm{s}}$ and $E<E_{\mathrm{eq}, b}$ occur $83 \%$ of the time, accounting for $45 \%$ of the overall wave energy). Regarding the similar mode, the remaining incident wave energy corresponding to $E_{\mathrm{eq}, \mathrm{s}}<E<E_{\mathrm{eq}, b}$ occurs only $10 \%$ of the time and accounts for $20 \%$ of the overall wave energy. The ratio of wave energy likely to drive the contrasting mode $(80 \%)$ over the wave energy likely to drive the similar mode (20\%) reflects the dominance of the contrasting mode (shoreline: $54 \%$; barline: $45 \%$ ) over the similar mode (shoreline: $10 \%$; barline: $20 \%$ ). This supports the association of the migration described by the contrasting and similar modes with the models' equilibrium theories.

Since Wright and Short [1984], it is not surprising that shoreline and barline cross-shore migrations occur simultaneously during beach state transitions. However, such simultaneity should only be partial since shoreline and barline are expected to adapt with different response time to changes in incident wave conditions. This is illustrated by recent attempts to model cross-shore sandbar migration, which showed that wave breaking over the bar crest was the main driver [Plant et al., 1999; Splinter et al., 2011; Blossier et al., 2016], which does not appear in shoreline models [Yates et al., 2009; Splinter et al., 2014]. For instance, in this paper, equations (5) and (7) lead, for steady conditions of wave energy $E_{0}$, to the following response times $\tau_{S_{0}}$ (shore) and $\tau_{B_{0}}$ (bar):

$$
\begin{gathered}
\tau_{S_{0}}=\frac{1}{C_{s} \sqrt{E_{0}} p_{s}}, \\
\tau_{B_{0}}=\frac{1}{C_{b} \sqrt{E_{0}} a_{b} f_{b}},
\end{gathered}
$$




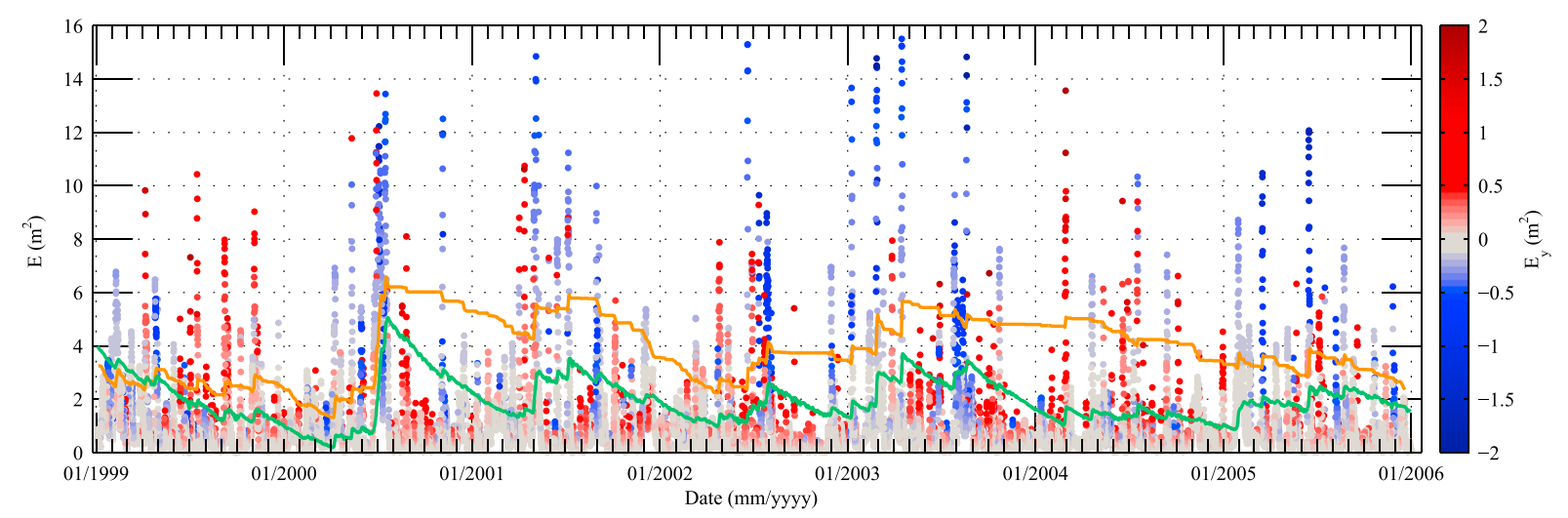

Figure 8. Orange line: Barline equilibrium energy $E_{\mathrm{eq}, b}$. Green line: Shoreline equilibrium energy $E_{\mathrm{eq}, s}$. Dots: Incident wave energy at $8 \mathrm{~m}$ depth (P2, Figure $1 \mathrm{~d}$ ). Colors indicate the corresponding amount of energy available for alongshore sediment transport $E_{y}$.

$$
\frac{\tau_{B_{0}}}{\tau_{s_{0}}}=\frac{C_{s} p_{s}}{C_{b} a_{b} f_{b}} \approx 0.2, \text { for } f_{b}=1 .
$$

$\tau_{S_{0}}$ ranges from above 80 days $\left(H_{s}<1 \mathrm{~m}\right)$ to below 20 days $\left(H_{s}>4 \mathrm{~m}\right)$. When waves break over the bar crest $\left(H_{s}>H_{b}\right.$ and $f_{b}=1$, i.e., barline seaward migration), the bar migrates at the maximal migration rate (about 5 times more quickly than the shoreline) toward its equilibrium position equation (14). During intermediate conditions $\left(E_{\mathrm{eq}, \mathrm{s}}<E<E_{\mathrm{eq}, b}\right.$ ), $\tau_{B_{0}}$ and $\tau_{s_{0}}$ get closer (average ratio of 0.8 ), so that the barline and shoreline still migrate together. However, during calm conditions, the barline model states that the barline should be nearly inactive (the term accounting for wave breaking, $f_{b}$ equation (8), leads to much slower response during calm conditions, with a ratio $\tau_{B_{0}}$ over $\tau_{S_{0}}$ above 10 for $70 \%$ of these conditions).

This does not fully agree with the PCA analyses that show that nearly all cross-shore migration is explained by simultaneous modes $\left(M_{1}^{*}\right.$ and $M_{2}^{*}$ ). However, the models do not perfectly simulate $M_{1}^{*}$ and $M_{2}^{*}$ (20\% of the variance is unexplained for the shoreline $\left(M_{1}^{*}\right)$ and for the barline $\left.\left(M_{2}^{*}\right)\right)$. This suggests the existence of processes that are not taken into account in the equilibrium theories; processes that may potentially couple the shoreline and the barline migrations, as suggested by Splinter et al. [2017]. Such processes would likely involve an influence of the bar on the hydrodynamics in the vicinity of the shoreline, especially on the wave field. For instance, the emergence of rip channels along the sandbar affects barline migration [Splinter et al., 2011] and can induce wave refraction, shoaling, and breaking patterns that can influence shoreline morphodynamics [Coco et al., 2005; Ruessink et al., 2007; Castelle et al., 2010a, 2010b; van de Lageweg et al., 2013]. On a larger scale, the overall barline state could play a role in the erosion (or accretion) at the shoreline [Price and Ruessink, 2011; Harley et al., 2015; Splinter et al., 2017]. Other processes such as the (unmodeled) breathing process mentioned earlier could also be involved.

\subsubsection{Rotation}

The PCA outcomes showed that the shoreline and the barline partly rotate simultaneously, in the same sense $\left(M_{1}^{*}\right)$. Such behavior can be explored using the equilibrium theories for rotation. Equation (6) associates shoreline rotation with the amount of wave energy contributing to alongshore transport $\left(E_{y}=E \cos (\theta) \sin (\theta)\right)$ while equation (9) relates barline rotation to alongshore wave energy gradients $\left(\nabla_{x}(E)\right.$ ). Therefore, the distributions of $E_{y}$ and $\nabla_{x}(E)$ corresponding to the wave energy conditions triggering the contrasting mode should relate to the associated directions of rotation.

When the contrasting mode $M_{1}^{*}$ is active, barline seaward migration and shoreline erosion are likely to occur with clockwise rotations (such as during Event I). This case is driven by storm conditions, $E>E_{\mathrm{eq}, \mathrm{s}}$ and $E>E_{\mathrm{eq}, b}$ (see previous section), for which the distributions of $E_{y}$ and $\nabla_{x}(E)$ are shifted within a quarter standard deviation toward negative values (for $E_{y}$, see the dominance of blue dots above $E_{e q, b}$, Figure 8 ). This favors simultaneous clockwise rotations of the shoreline and barline (Figure 6a).

The contrasting mode $M_{1}^{*}$ also describes beach recovery (barline shoreward migration, shoreline accretion), which it associates with counterclockwise rotations (such as during Event II). This case occurs when $E<E_{\text {eq,s }}$ and $E<E_{\text {eq,b }}$ (see previous section). Under these conditions, the distributions of $E_{y}$ and $\nabla_{x}(E)$ have averaged values close to zero and standard deviations about 5 times smaller than during energetic conditions. 

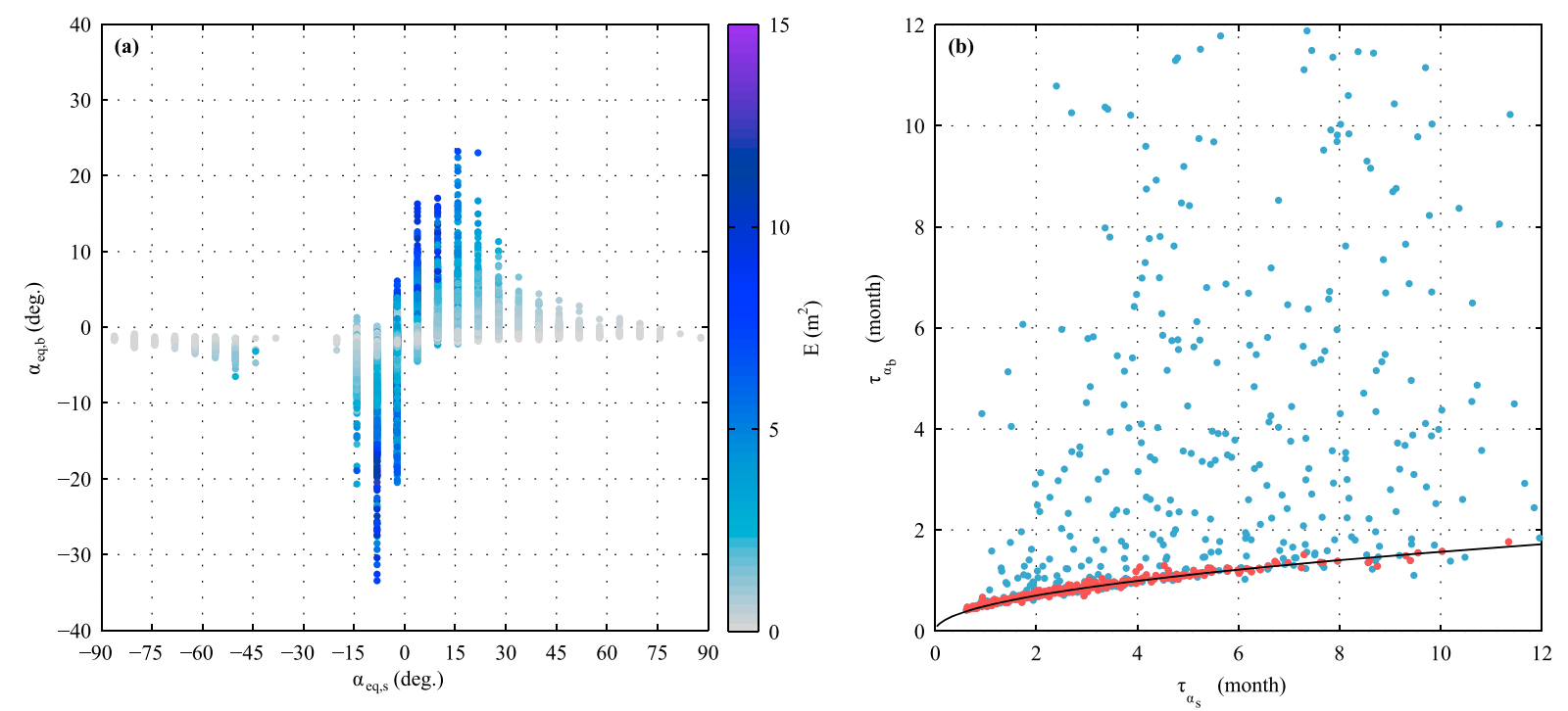

Figure 9. (a) Equilibrium orientation of the barline $\alpha_{\text {eq,b }}$ (equation (16)) on the vertical axis as a function of the equilibrium orientation of the shoreline (equation (15)). Values are given in degrees. The color scale indicates the intensity of the incident wave energy. (b) Red and blue dots represent the response time of the barline orientation $\tau_{\alpha_{b}}$ as a function of the shoreline orientation $\tau_{\alpha_{s}}$ (only values shorter than 12 months are shown). Red dots correspond to a damping factor $f_{b}=1$ and a limited wave incidence $|\theta|<10^{\circ}$. The black line represents the relation between $\tau_{\alpha_{b}}$ and $\tau_{\alpha_{s}}$ for $f_{b}=1$ and $\theta=0$ (equation (19)).

Therefore, after a storm event during which the shoreline and barline rotated clockwise, these tend to rotate back toward a near-zero orientation during recovery; i.e., they rotate counterclockwise. In addition, the distribution of $E_{y}$ shows a significant positive skewness (see the large number of red dots below $E_{\mathrm{eq}, s^{\prime}}$ Figure 8 ) that can enhance counterclockwise rotation during shoreline accretion (Figure 6b).

Little rotation is explained by the similar mode $M_{2}^{*}$ (Figures $5 f$, and $5 \mathrm{j}$, and $R_{R}^{2}$ in Table 2 ). This mode is active when $E_{\text {eq, } s}<E<E_{\text {eq, } b}$ (see previous section). In agreement with the PCA, these conditions correspond to slightly negative averaged values of $E_{y}$ and $\nabla_{x}(E)$ that are negligible compared to standard deviations ( 1 order of magnitude). The relations between wave climate properties and the activation of modes $M_{1}^{*}$ and $M_{2}^{*}$ are summarized in Figure 6.

Despite the simultaneous rotation patterns discussed above, the PCA outcomes showed that shoreline and barline rotations are strongly nonsimultaneous $\left(R_{R}^{2}\right.$ about $10 \%$ for $M_{3}^{*}$ and $M_{4}^{*}$, i.e., 30 and $60 \%$ of the shoreline and barline rotation, respectively), and so we should expect them to behave independently. In addition, $M_{3}^{*}$ and $M_{4}^{*}$ show that rotation can occur without substantial migration, such as during Event III. The rotation models' formulations support these observations by involving different physical processes, which do not relate to the shoreline or barline migration. The shoreline rotation is driven by $E_{y}$, representing alongshore sediment transport induced by longshore currents, while barline rotation is driven by $\nabla_{x}(E)$, which relates to a differential adaptation of the cross-shore position of the barline along the beach via cross-shore processes. Consequently, shoreline and barline rotations should respond toward different equilibrium orientations with different response times, explaining the emergence of nonsimultaneous modes.

Under steady wave conditions (incident wave energy $E_{0}$ and wave angle $\theta_{0}$ ), equilibrium orientations $\alpha_{\text {eq,s }}$ and $\alpha_{\text {eq,b }}$ can be inferred from equations (6) and (9) for the shoreline and barline, respectively:

$$
\begin{gathered}
\alpha_{\text {eq }, s}=\theta_{0}, \\
\alpha_{\text {eq }, b}=\alpha_{e q}+\frac{1}{\delta_{b} a_{b}} \frac{\partial E_{0}}{\partial x},
\end{gathered}
$$

These two quantities are represented in Figure 9a with their corresponding incident wave energy. While $\alpha_{\text {eq,s }}$ relates directly to the wave angle of incidence, in agreement with Turki et al. [2013a, 2013b] and Blossier et al. [2015], $\alpha_{\text {eq,b }}$ relates to the alongshore wave energy gradient, in agreement with Bryan et al. [2013] and Blossier et al. [2016]. 
Simultaneous shoreline and barline rotation patterns would suppose a nearly constant ratio between shoreline and barline rotation rates. This is more likely to be the case if $\alpha_{\text {eq, } s}$ and $\alpha_{\text {eq, } b}$ are correlated. However, Figure 9a shows that wave energy strongly influences the relationship between $\alpha_{\text {eq, } s}$ and $\alpha_{\text {eq }, b}$. The average ratio $\alpha_{\text {eq, } b}$ over $\alpha_{\text {eq, },}$ decreases with decreasing wave energy ( 2 for $E \geq 10 \mathrm{~m}^{2}, 1.5$ for $5 \leq E<10 \mathrm{~m}^{2} ; 0.7$ for $2.5 \leq E<5 \mathrm{~m}^{2} ; 0.23$ for $1 \leq E<2.5 \mathrm{~m}^{2}$, ( $\left.R^{2} \geq 0.6\right)$ ). For incident wave energy below $1 \mathrm{~m}^{2}$, there is no significant correlation and $\alpha_{\text {eq, } b}$ falls between $-9^{\circ}$ and $5^{\circ}$ for any value of $\alpha_{\text {eq, },}$.

This explains why strong rotations of the bar are observed during storms even at low angles of incidence, such as Events I and IV (Figure 3). During these events, high waves $\left(H_{s}=3.8\right.$ and $3 \mathrm{~m}$, respectively, Figure $2 \mathrm{a}$ ) and low angle of incidence $\left(\theta \sim-5^{\circ}\right.$ and $-2^{\circ}$, respectively, not shown) induce large alongshore negative gradients of wave energy ( -2.5 and $-1 \mathrm{~m}^{2} / \mathrm{m}$, Figure $2 \mathrm{c}$ ) driving large clockwise barline rotation, while clockwise shoreline rotation is limited for Event I and does not occur for Event IV ( $E_{y}$ close to 0, Figure $2 \mathrm{~b}$ ). Conversely, under low wave conditions, regardless of the wave angle, low alongshore wave energy gradients lead to a rotation of the bar toward $\alpha_{\text {eq,b }} \sim \alpha_{\text {eq }}=-0.028$ (equation (16), see Figure 3, year 1999, August 2000 to February 2001, and year 2004).

Not only can the shoreline and barline equilibrium angles induce nonsimultaneity of the shoreline and barline rotations but also their characteristic response times toward equilibria, $\tau_{\alpha_{s}}$ and $\tau_{\alpha_{b}}$, respectively:

$$
\begin{aligned}
\tau_{\alpha_{s}} & =\frac{1}{C_{\alpha_{s}} E_{0} \cos \left(2 \theta_{0}\right)}, \\
\tau_{\alpha_{b}} & =\frac{1}{C_{\alpha_{b}} \sqrt{E_{0}} f_{b} \delta_{b} a_{b}}, \\
\tau_{\alpha_{b}}=\frac{\sqrt{C_{\alpha_{s}}}}{C_{\alpha_{b}} \delta_{b} a_{b}} \sqrt{\tau_{\alpha_{s}}} & \approx 2.7 \sqrt{\tau_{\alpha_{s}}}, \text { for } f_{b}=1 \text { and } \theta_{0}=0 .
\end{aligned}
$$

Values of $\tau_{\alpha_{s}}$ and $\tau_{\alpha_{b}}$ are represented in Figure 9b. Equation (19) provides the relation between $\tau_{\alpha_{s}}$ and $\tau_{\alpha_{b}}$ for energetic conditions (waves break offshore of the bar crest, i.e., $f_{b}=1$ ), and near-normal wave incidence. Under these conditions, mode $M_{1}^{*}$ is active. The barline orientation responds much more quickly than the shoreline orientation and oblique wave angles can even increase this difference (dots below the black line, Figure $9 b)$. However, the beach experiences more often calm conditions $\left(f_{b}<1\right)$. As a result, in the models, $\tau_{\alpha_{b}}>\tau_{\alpha_{s}}$ for $75 \%$ of the evaluated time steps, showing that the barline is less active than the shoreline in general, inducing nonsimultaneous rotations.

To summarize, shoreline and barline rotations are partly simultaneous, as shown by $M_{1}^{*}$, partly nonsimultaneous, as shown by $M_{3}^{*}$ and $M_{4}^{*}$. Simultaneity can be associated with the partial correlation of $E_{y}$ and $\nabla_{x}(E)$, driving the shoreline and barline rotation, respectively. However, this correlation depends on the wave energy, resulting in wave energy-dependent relationships between equilibrium angles $\alpha_{\text {eq,s }}$ and $\alpha_{\text {eq, } b}$ and response times $\tau_{\alpha_{s}}$ and $\tau_{\alpha_{b}}$. This contributes to the nonsimultaneity of the shoreline and barline rotations.

Drivers behind beach rotation are regularly questioned in the literature [Harley et al., 2011; Bryan et al., 2013; Turki et al., 2013b; Harley et al., 2015; Blossier et al., 2016]. Here at Tairua Beach, the good agreement between the PCAs and equilibrium models' outcomes argues in favor of the wave oblique incidence and consequent longshore transport to be the main driver of shoreline rotation. It also confirms that barline rotation is likely to be driven by the cross-shore adaptation of the barline position to alongshore wave energy gradients. Shoreline rotation due to upper beach steepening or flattening induced by wave energy gradients is ignored in the present shoreline rotation model. It would induce rotations in opposite sense compared to observations (i.e., opposed to sandbar sense of rotation), and so may only occur in a very limited manner (among $21 \%$ of shoreline rotation unexplained by the model, Table 1). Shoreline and barline rotations seem to be coupled mainly via the coupling of the wave field parameters $E_{y}$ and $\nabla_{x}(E)$. This strongly infers the importance of the local geological setting in the observed embayment-wide rotation patterns.

\section{Conclusion}

This study explored the potential coupling of the shoreline and sandbar of a single-barred embayed beach. A combined approach based on the outcomes of two different PCA methods and four equilibrium models has been used to characterize the dominant coupled patterns of the shoreline and barline. Classical PCAs showed 
that dominant patterns occur at the scale of the embayment and are combinations of cross-shore migrations and rotations of the beach shoreline and sandbar.

A new application of PCA leads to a quantification of how much of these patterns were induced simultaneously by the shore and bar dynamics. The two major coupled dynamical patterns that were isolated were beach transitions toward more reflective or more dissipative states (contrasting mode) and shoreline and barline cross-shore migrations in identical directions (similar mode). This similar mode also involved a breathing of the barline, showing that breathing modes are not limited to shoreline morphodynamics.

A general good agreement between data- and model-based PCA modes indicates that equilibrium models can capture and describe the dominant scales of motion, i.e., the dynamic patterns at the embayment scale that involve simultaneous or nonsimultaneous shore and bar behaviors. According to the theories underlying the models, cross-shore migrations of the shoreline and barline are mainly controlled by the incident wave energy intensity while shoreline rotation is driven by the wave angle of incidence and consequent longshore sediment transport. Barline rotation is driven by alongshore wave energy gradients and cross-shore sediment transport.

The contrasting mode reveals the nature of the simultaneous shore and barline behavior. The simultaneity in shore and bar cross-shore migration can be either explained by the fact that they obey the same driver, i.e., the wave energy intensity, or because these features can be physically coupled by, for instance, the influence of the sandbar on the shoreline hydrodynamics or cross-shore transfers of sediment. During higher wave energy conditions, the alongshore gradient in wave height (which drives barline rotation) and the alongshore wave energy flux (which drives shoreline rotation) are activated together, which results in rotations in identical sense that depends on the local wave climate properties. Wave angles and alongshore gradients in wave height can be related because of the geological setting (for example, when changes in the wave angles also cause one end of the beach to get shadowed by a headland or island).

Drivers identified in this study are likely to occur at any intermediate single-barred embayed beach, suggesting that coupled, embayment-wide shoreline and sandbar patterns can probably be observed in such environments. However, the occurrence of similar patterns at multiple-barred beaches, involving the shoreline and multiple sandbars, remains largely unexplored. The PCA method used in the present study could be an efficient approach to assess if such patterns occur, and to evaluate the role of intermediate sandbars, located between the shoreline and the outermost sandbar.

\section{Appendix A: Influence of Errors on the Results}

The influence of measurement errors on the PCAs of this study was assessed. One hundred surrogate shoreline and barline signals were generated by superimposing noise signals to the original signals. For the shoreline, a nearly Gaussian noise in time and space, $\mathcal{N}_{s, \text { pixel }}\left(x_{s}, t\right)$ was generated with a standard deviation of $0.4 \mathrm{~m}$ and a maximum amplitude of $0.7 \mathrm{~m}$ to simulate the pixel footprint accuracy. This was added to an alongshore-uniform Gaussian noise in time, $\mathcal{N}_{\text {s,runup }}(t)$ with a standard deviation of $3.5 \mathrm{~m}$ to simulate the uncertainty in water level (including tidal level, wave setup and runup). For the barline, an alongshore-uniform Gaussian noise in time, $\mathcal{N}_{b \text {,error }}(t)$ with a standard deviation of $10 \mathrm{~m}$, was used to account for the overall error in bar digitization.

Overall, the spatial vectors $e_{s, i}, e_{b, i}, e_{s, i^{\prime}}^{*}$ and $e_{b, i}^{*}$ are nearly unchanged (not shown). Largest (but still very small) changes are observed for $e_{b, 3}^{*}$ and $e_{s, 4^{\prime}}^{*}$ which were found to be the trivial part of nonsimultaneous modes $M_{3}^{*}$ and $M_{4}^{*}$ in the main text. Changes in $R^{2}$ values are usually $\pm 1-2 \%$, always below $5 \%$ except for $M_{2}^{*}$ (up to $+8 \%$ for the shoreline). Larger differences are found within the temporal vectors $c_{s, i}, c_{b, i^{\prime}} c_{s, i^{\prime}}^{*}$ and $c_{b, i^{*}}^{*}$ Indeed, with unchanged spatial vectors and $R^{2}$ values, they reflect directly the synthetic noise in the signals.

\section{Appendix B: Significance of PCA Modes}

The rule of thumb of North et al. [1982] is commonly applied to identify sets of degenerated modes within a PCA analysis. In such a set, any linear combination of modes is as significant as one of them, yielding to difficult interpretations [Hannachi et al., 2007; Reeve et al., 2008; Wilks, 2011; Karunarathna et al., 2012]. In theory these degenerated modes should have the same eigenvalue $\left(\lambda_{s, i}, \lambda_{b, i}\right.$ in equations (1) and (2)). The rule of thumb 
proposes a formulation of the error in the computation of eigenvalues and states that modes are degenerated if the spacing between successive eigenvalues falls within this error. The error $\delta_{\lambda_{i}}$ for eigenvalue $\lambda_{i}$ is given by

$$
\delta_{\lambda_{i}}=\sqrt{\frac{2}{N *}} \lambda_{i}
$$

where $N *$ is the number of independent samples of the data set, related to the total number of samples $N$ by the autocorrelation coefficient of the time series [Zwiers and von Storch, 1995]. A mode is significant if

$$
\lambda_{i}-\lambda_{i+1}<\delta_{\lambda_{i}}
$$

In addition to the rule of thumb, a Monte Carlo approach based on surrogate data is used here to assess the significance of the modes at the $95 \%$ level. It is assumed that the beach morphodynamics behave as a red noise in time, which is confirmed by comparing the spectra of beach characteristics (not shown for the shoreline; see Blossier et al. [2016] for the barline] to a red noise spectrum. Then for each time step, the spectral decomposition of the beach shoreline (or barline) is computed. Phases are randomly shifted and a new profile is generated by performing an inverse Fourier transform resulting in a full set of profiles $S^{\prime}\left(x_{s}, t\right)$ $\left(B^{\prime}\left(x_{b}, t\right)\right)$ spectrally equivalent to the observed profiles $S\left(x_{s}, t\right)\left(B\left(x_{b}, t\right)\right)$, for the shoreline (barline), respectively. For instance, for the shoreline, the red noise-based surrogate signal $S_{n}$ is then generated by

$$
S_{n}\left(x_{s}, t+\Delta t\right)=r_{1}\left(x_{s}\right) S\left(x_{s}, t\right)+S^{\prime}\left(x_{s}, t+\Delta t\right)
$$

where $\Delta t$ is the data set sampling time and $r_{1}\left(x_{s}\right)$ is a vector of the first autocorrelation coefficient (in time) at each alongshore position. A thousand surrogate signals $S_{n}$ are generated. The $95 \%$ level of significance is determined at alongshore position $x_{s}$ by computing the $95 \%$ percentile of the $R^{2}\left(x_{s}\right)$ coefficients computed between measured $\left(S\left(x_{s}, t\right)\right)$ and generated $\left(S_{n}\left(x_{s}, t\right)\right)$ signals. For both the shoreline and barline, $R^{2}$ values fall below $5 \%$, showing that any mode explaining more that $5 \%$ of variability is significant.

\section{Appendix C: Semiempirical Models}

\section{C1. Formulations}

Four semiempirical models based on existing literature are used in the present study to simulate the morphodynamics of Tairua Beach in terms of alongshore-averaged cross-shore position and orientation of both the beach shoreline and barline. This appendix focuses on shoreline models. Concerning the barline cross-shore and rotation models, we refer the reader to the work of Blossier et al. [2016] that provides extensive details about their formulation, calibration, and validation. The same parameters are used in the present work.

The shoreline model that describes the cross-shore position of the beach shoreline is based on the formulation of Yates et al. [2009]. Here using different coefficients quantifying accretion and erosion rates of the shoreline did not improve the performance of the model and therefore, only one is used. However the model was found not to be able to describe long-term trends. As such, the shoreline position $S_{0}$ is decomposed as a part described by the model $S_{0}^{\prime}$ and a linear trend, similar to Davidson et al. [2013]:

$$
\begin{gathered}
S_{0}=q_{s} t+m_{s}+S_{0}^{\prime}, \\
E_{\mathrm{eq}, s}=p_{s} S_{0}^{\prime}+n_{s}, \\
\frac{\partial S_{0}^{\prime}}{\partial t}=C_{s} \sqrt{E}\left(E-E_{\mathrm{eq}}\right)=C_{s} \sqrt{E}\left(E-p_{s} S_{0}^{\prime}-n_{s}\right)
\end{gathered}
$$

where $q_{s}\left(\mathrm{~m} \mathrm{~s}^{-1}\right)$ is the linear trend coefficient, $m_{s}(m)$ is an offset, $E_{\text {eq }}$ is the equilibrium energy linearly depending on the current position of the shoreline $S_{0}^{\prime}$ with coefficients $p_{s}(m)$ and $n_{s}\left(m^{2}\right)$. $E$ is the incident wave energy at time $t$ and $C_{s}\left(\mathrm{~m}^{-2} \mathrm{~s}^{-1}\right)$ is a calibration coefficient. In this appendix, unlike in the main text, notation $\sim$ is not used to mark modeled values such as $S_{0}$.

Equations (C1) and (C3) can be alongshore-averaged using the following hypotheses:

1. The shoreline linear trend is uniform in the embayment ( $q_{s}$ and $m_{s}$ are constant).

2. $p_{s}$ and $n_{s}$ are symmetric in the embayment.

3. $C_{s}$, controlling the accretion and erosion rates, is constant in the embayment.

4. $E$ and $S_{0}^{\prime}$ can be linearized with an alongshore-averaged value $\left(\bar{E}, \overline{S_{0}}\right)$, and an alongshore-varying value $\left(\check{E}, \check{S}_{0}\right)$ 5. $\breve{E} \ll \bar{E}$ 
Table C1. Shoreline Migration and Rotation Models Coefficients and Skill for the 7 Year and Five 3 Year Long Time Periods

\begin{tabular}{|c|c|c|c|c|c|c|c|c|c|}
\hline \multirow[b]{2}{*}{ Time } & \multicolumn{6}{|c|}{ Migration } & \multicolumn{3}{|c|}{ Rotation } \\
\hline & $\begin{array}{c}C_{s} \\
\left(m^{-2} s^{-1}\right)\end{array}$ & $\begin{array}{l}p_{s} \\
(\mathrm{~m})\end{array}$ & $\begin{array}{c}q_{s} \\
(\mathrm{~m} / \mathrm{yr})\end{array}$ & $\begin{array}{c}r_{s} \\
\left(\mathrm{~m}^{2}\right)\end{array}$ & $\begin{array}{l}R^{2} \\
-\end{array}$ & $\begin{array}{c}\text { Bss } \\
-\end{array}$ & $\begin{array}{c}C_{\alpha_{s}} \\
\left(m^{-2} s^{-1}\right)\end{array}$ & $\begin{array}{c}R^{2} \\
-\end{array}$ & $\begin{array}{c}\text { Bss } \\
-\end{array}$ \\
\hline 1999-2006 & -0.079 & -0.084 & -1.81 & 5.73 & 0.67 & 0.64 & 0.004 & 0.79 & 0.62 \\
\hline 1999-2002 & -0.061 & -0.026 & -0.51 & 3.31 & 0.84 & 0.84 & 0.006 & 0.89 & 0.30 \\
\hline $2000-2003$ & -0.064 & -0.107 & -2.37 & 7.02 & 0.79 & 0.78 & 0.006 & 0.88 & 0.32 \\
\hline $2001-2004$ & -0.086 & -0.119 & -3.03 & 7.79 & 0.72 & 0.71 & 0.006 & 0.86 & 0.64 \\
\hline $2002-2005$ & -0.127 & -0.088 & -1.05 & 5.54 & 0.74 & 0.73 & 0.004 & 0.81 & 0.62 \\
\hline $2003-2006$ & -0.118 & -0.067 & -3.40 & 5.61 & 0.75 & 0.74 & 0.004 & 0.80 & 0.61 \\
\hline Average & -0.091 & -0.082 & -2.07 & 5.85 & 0.77 & 0.76 & 0.005 & 0.85 & 0.50 \\
\hline Standard deviation & \pm 0.030 & \pm 0.037 & \pm 1.25 & \pm 1.71 & \pm 0.05 & \pm 0.05 & \pm 0.001 & \pm 0.04 & \pm 0.17 \\
\hline
\end{tabular}

Using a Taylor expansion of $\sqrt{\bar{E}+\breve{E}}$, equations (C1) and (C3) become

$$
\begin{gathered}
\overline{S_{0}}=q_{s} t+m_{s}+\overline{S_{0}^{\prime}}, \\
\frac{\mathrm{d} \overline{S_{0}^{\prime}}}{\mathrm{d} t}=C_{s} \sqrt{\bar{E}}\left(\bar{E}-\overline{p_{s}} \overline{S_{0}^{\prime}}-\overline{n_{s}}\right)+O\left(\frac{\overline{\check{E}^{2}}}{\sqrt{\bar{E}}}\right)
\end{gathered}
$$

The last term is indeed negligible for more than $94 \%$ of the modeled wave conditions.

Combining equations (C4) and (C5) leads to the following model for $\overline{S_{0}}$ :

$$
\begin{gathered}
\frac{\mathrm{d} \overline{S_{0}}}{\mathrm{~d} t}=C_{s} \sqrt{\bar{E}}\left(\bar{E}-\overline{p_{s}} \overline{S_{0}}-\overline{n_{s}}+\overline{p_{s}} q_{s} t+\overline{p_{s}} m_{s}\right)+q_{s}, \\
=C_{s} \sqrt{\bar{E}}\left(\bar{E}-\overline{p_{s}} \overline{S_{0}}+\overline{p_{s}} q_{s} t-r_{s}\right)+q_{s}, \\
r_{s}=\overline{n_{s}}-\overline{p_{s}} m_{s}
\end{gathered}
$$

where the migration rate depends now on four free coefficients $C_{s}, \overline{p_{s}}, q_{s}$, and $r_{s}$. Symbol ${ }^{-}$for alongshore averaging is ignored in the main text and in the following.

The second model describes the rotation of the shoreline, and its formulation is based on the results of a statistical linear analysis [Blossier et al., 2015] showing a clear relationship between the shoreline rotation rate and the amount of wave energy available for alongshore sediment transport [Komar and Inman, 1970]. These observations are in agreement with the model of Turki et al. [2013b], and therefore, the present shoreline rotation model is a simplified formulation of their model assuming an equilibrium orientation of the beach shoreline perpendicular to the incoming wave direction $\theta$. The formulation of Turki et al. [2013b] is

$$
\frac{\mathrm{d} \alpha_{s}}{\mathrm{~d} t}=2 \frac{K}{L^{2} h^{*}} \rho_{w} g H_{b, 0}^{2} c_{g, b} \sin \left(\theta-\alpha_{s}\right) \cos \left(\theta-\alpha_{s}\right),
$$

with $\alpha_{s}$ the shoreline orientation, $K\left(\mathrm{~m}^{2} \mathrm{~s}^{2} \mathrm{~kg}^{-1}\right)$ a coefficient accounting for the sediment properties, $L(\mathrm{~m})$ the length of the shoreline, $h^{*}(\mathrm{~m})$ the closure depth, $\rho_{w}\left(\mathrm{~kg} \mathrm{~m}^{-3}\right)$ the water density, $g\left(\mathrm{~m} \mathrm{~s}^{-2}\right)$ the gravity acceleration, $H_{b}(\mathrm{~m})$ the breaking wave height, and $c_{g, b}\left(\mathrm{~m} \mathrm{~s}^{-1}\right)$ the wave group celerity at breaking. Linearly expanded to the first order for small values of $\alpha_{s}$, using wave height values at $8 \mathrm{~m}$ depth and neglecting the variations of the wave group celerity, the formulation is simplified to

$$
\frac{\mathrm{d} \alpha_{s}}{\mathrm{~d} t}=C_{\alpha_{s}} E\left[\sin (\theta) \cos (\theta)-\alpha_{s} \cos (2 \theta)\right]
$$

with $C_{\alpha_{s}}\left(\mathrm{~m}^{-2} \mathrm{~s}^{-1}\right)$ a free parameter of the model. 


\begin{tabular}{lllllllllll} 
Table C2. Models Skills for 2 Year Forecasts With Increasing Training Periods \\
Training & $\overbrace{\text { RMSE }}^{\text {S }}$ & $R^{2}$ & $\overbrace{\text { RMSE }}^{S_{0}}$ & $R^{2}$ & $\overbrace{\text { RMSE }}^{\alpha_{S}}$ & $R^{2}$ & $\overbrace{\text { RMSE }}^{B_{0}}$ & $R^{2}$ \\
\hline $1999-2000$ & 9.7 & 0.11 & 0.013 & 0.83 & 18.4 & 0.66 & 0.049 & 0.62 \\
$1999-2001$ & 4.8 & 0.34 & 0.010 & 0.91 & 21.6 & 0.40 & 0.029 & 0.78 \\
$1999-2002$ & 4.0 & 0.70 & 0.009 & 0.90 & 19.6 & 0.45 & 0.038 & 0.70 \\
$1999-2003$ & 4.4 & 0.59 & 0.007 & 0.78 & 16.6 & 0.35 & 0.036 & 0.62 \\
$1999-2004$ & 3.9 & 0.57 & 0.008 & 0.56 & 13.9 & 0.44 & 0.034 & 0.70 \\
\hline
\end{tabular}

\section{C2. Performance}

Performance was evaluated using two different approaches. First the models were calibrated using the entire 7 year shoreline data set and five 3 year data sets. The resulting hindcasts were compared to the observations (Table C1). Then they were trained over 1 to 5 years of data, and the skill of the forecasts was evaluated on the two successive years (Table C2).

The semiempirical models (shoreline migration and rotation) hindcast the 7 year beach behavior with fair to good skill (about $70 \%$ of variance explained (Table C1), Brier skill scores about 0.6, i.e., a fair to good fit, according to van Rijn et al. [2003]). These results are confirmed by the runs on 3 year data sets (Table C1). The coefficients of the models presented in Table $\mathrm{C} 1$ are quite stable over the different calibration period. In particular, average values of the coefficients over the five 3 year calibration periods are similar to the coefficients obtained for the 7 year calibration.

Then, models were validated using 2 year simulations after a 1 to 5 year calibration period. RMSE values and $R^{2}$ coefficients are provided in Table C2. The four models perform reasonably for 3 years of training or more. In this case, root-mean-square errors are systematically below the standard deviations of the observed parameters and $R^{2}$ coefficients range from 0.35 to 0.90 .

\section{Appendix D: Contribution of PCA Modes to Migration, Rotation, and Change of Curvature}

Table 2 presents the contributions of the different PCA modes computed in this study to the shoreline and barline signals, in terms of migration, rotation, and change of curvature. This is achieved by first evaluating the $R^{2}$ coefficients between the spatial vectors computed in sections 4.1 and $4.2\left(e_{s, i}, e_{b, i}, e_{s, i}^{*}\right.$ and $\left.e_{b, i}^{*}\right)$ and three normalized "idealized" orthogonal vectors (ideal shoreline/barline shapes).

These three idealized vectors represent an alongshore-uniform shape, an oblique shape with zero mean, and a hyperbolic cosine-shaped shape with zero mean. Therefore, their time variation would represent a migration, a rotation, and a breathing [Ratliff and Murray, 2014]. These profiles have been selected as they represent the most common behavior of embayed beach shoreline and barline found in the literature; they correspond to the model abilities (migration and rotation simulation) and to the preliminary observations (see section 2.3).

At this point, $R^{2}$ values only reflect how the mode variability is spread over migration, rotation, and change of curvature (for instance, $80 \%$ describes migration, $10 \%$ describes rotation, $5 \%$ describes curvature variations, and $5 \%$ describes other patterns). To relate this to the shoreline or barline variability, these $R^{2}$ values are scaled by the variability explained by each mode (columns $R^{2}$ in Table 2, also found in Figure 5). Resulting coefficients $R_{M^{\prime}}^{2} R_{R^{\prime}}^{2}$ and $R_{U}^{2}$ quantify the contributions of each mode to the shoreline or barline variability, in terms of migration, rotation, and curvature variations. For instance, $M_{s, 1}$ explains $64 \%$ of the shoreline variability, which can be decomposed into $41 \%$ in terms of migration and $23 \%$ in terms of rotation.

\section{Notation}

$a_{b}$ free parameter, $\mathrm{m}$.

$\alpha_{b}$ barline orientation (slope of the linear fit to each barline profile).

$\alpha_{\text {eq }}$ free parameter,

$\alpha_{\text {eq, }, s^{\prime}} \alpha_{\text {eq, } b}$ equilibrium shoreline and barline orientations,

$\alpha_{s}$ shoreline orientation (slope of the linear fit to each shoreline profile), 
$B_{0}$ barline alongshore-averaged cross-shore position, $\mathrm{m}$.

$B\left(x_{b}, t\right)$ barline cross-shore position, described over alongshore dimension and time, $\mathrm{m}$.

$b_{b}$ free parameter, $\mathrm{m}^{2}$.

Bss Brier Skill Score.

$C$ stacked shoreline and barline signal for PCA using Method 2,

$c_{i}^{*}$ temporal vectors of PCA mode $i$, Method 2,

$c_{b, i}, c_{s, i}$ temporal vectors of barline and shoreline, respectively (modes $i$, Method 1 ),

$c_{g, b}$ wave group celerity at breaking, $\mathrm{m} \mathrm{s}^{-1}$.

$C_{\alpha_{b}}$ free parameter, $\mathrm{m}^{-2} \mathrm{~s}^{-1}$.

$C_{\alpha_{s}}$ free parameter, $\mathrm{m}^{-2} \mathrm{~s}^{-1}$.

$C_{b}$ free parameter, $\mathrm{m}^{-2} \mathrm{~s}^{-1}$.

$C_{s}$ free parameter, $\mathrm{m}^{-2} \mathrm{~s}^{-1}$.

$d_{50}$ median grain size, $\mu \mathrm{m}$.

$\delta$ embayed beaches classification parameter,

$\delta_{b}$ free parameter,

$\delta_{\lambda_{i}}$ uncertainty of PCA eigenvalue $\lambda_{i}$,

$E$ incident wave energy defined as the square of the significant wave height $H_{s}, \mathrm{~m}^{2}$.

$E_{0}$ steady wave energy condition, $\mathrm{m}^{2}$.

$e_{b, i}^{*}, e_{s, i}^{*}$ splitted spatial vectors from $e_{i}^{*}$ (mode $i$, Method 2), for barline and shoreline,

$e_{i}^{*}$ spatial vectors of stacked shoreline and barline (mode $i$, Method 2 ),

$e_{b, i}, e_{s, i}$ spatial vectors of barline and shoreline, respectively (modes $i$, Method 1 ),

$E_{e q, b}$ equilibrium wave energy corresponding to the instantaneous barline position, $\mathrm{m}^{2}$.

$E_{e q, s}$ equilibrium wave energy corresponding to the instantaneous shoreline position, $\mathrm{m}^{2}$.

$E_{y}$ wave energy available for alongshore sediment transport, $\mathrm{m}^{2}$.

$f_{b}$ damping factor.

$g$ gravity acceleration, $\mathrm{m} \mathrm{s}^{-2}$.

$H_{b}$ breaking wave height over the bar crest, $\mathrm{m}$.

$H_{b, 0}$ breaking wave height, $\mathrm{m}$.

$h^{*}$ closure depth, $\mathrm{m}$.

$H_{s}$ significant wave height, $\mathrm{m}$.

$K$ coefficient accounting for sediment properties,

$\lambda_{b, i}, \lambda_{s, i}$ PCA eigenvalues for the barline and shoreline, Method 1,

$\lambda_{i}$ PCA eigenvalue,

$\lambda_{i}^{*}$ PCA eigenvalue, Method 2,

$L$ beach length, $\mathrm{m}$.

$L_{b}, L_{s}$ alongshore positions of the center of the barline and shoreline, $\mathrm{m}$.

$M_{i}^{*}$ PCA modes $i$ of stacked shore- and barline, Method 2,

$M_{b, i}, M_{s, i}$ PCA modes $i$ of barline and shoreline, Method 1,

$m_{s}$ offset, $\mathrm{m}$.

$\nabla_{x}(E)$ alongshore gradient of wave energy, $\mathrm{m}$.

$\mathcal{N}_{b, \text { error }}$ Gaussian noise simulating barline position measurement error, $\mathrm{m}$.

$\mathcal{N}_{s, \text { pixel }}$ Gaussian noise simulating pixel footprint error, $\mathrm{m}$.

$\mathcal{N}_{\text {s,runup }}$ Gaussian noise simulating runup evaluation error, $\mathrm{m}$.

$N^{*}$ number of independent samples of a data set,

$n_{s}$ free parameter, $\mathrm{m}^{2}$.

$p$ parameter used in the formulation of the damping factor, 8 .

$p_{s}$ free parameter, $\mathrm{m}$.

$q_{s}$ linear trend coefficient, $\mathrm{m} \mathrm{s}^{-1}$ (given in $\mathrm{m} \mathrm{yr}^{-1}$ in Table C1).

$r_{1}$ first autocorrelation coefficient,

$r_{s}$ free parameter, $\mathrm{m}^{2}$.

$R^{2}$ squared correlation coefficient.

$R_{M^{\prime}}^{2} R_{R^{\prime}}^{2} R_{U}^{2}$ variance explained by PCA modes in terms of migration, rotation, and breathing,

$\rho_{w}$ water density, $\mathrm{kg} \mathrm{m}^{-3}$.

RMAE relative mean average error.

RMSE root-mean-square error. 
$\sigma$ standard deviation, $\mathrm{m}$.

$\mathrm{S}_{0}$ shoreline alongshore-averaged cross-shore position, $\mathrm{m}$.

$S_{0}^{\prime}$ detrended shoreline alongshore-averaged cross-shore position, $\mathrm{m}$.

$S_{n}\left(x_{s}, t\right)$ surrogate shoreline cross-shore position signal $n$, described over alongshore dimension and time, $\mathrm{m}$.

$S(x, t)$ shoreline cross-shore position, described over alongshore dimension and time, $\mathrm{m}$.

$S^{\prime}\left(x_{s}, t\right)$ synthetic shoreline cross-shore position, described over alongshore dimension and time, $\mathrm{m}$.

$t$ time, s.

$\tau_{\alpha_{b}}$ instantaneous characteristic response time of the barline rotation, day.

$\tau_{\alpha_{s}}$ instantaneous characteristic response time of the shoreline rotation, day.

$\tau_{B_{0}}$ instantaneous characteristic response time of the barline cross-shore migration, day.

$\tau_{S_{0}}$ instantaneous characteristic response time of the shoreline cross-shore migration, day.

$\theta$ peak incident wave angle,

$\theta_{0}$ steady peak incident wave angle condition,

$T_{m}$ mean wave period,

$x$ alongshore dimension in the local reference frame, increasing southward, $\mathrm{m}$.

$x_{b}, x_{s}$ alongshore vectors on which the barline and shoreline are defined, $\mathrm{m}$.

$x_{b, \text { norm }} x_{b}$ normalized to the size of $x_{s}, \mathrm{~m}$.

$y$ cross-shore dimension in the local reference frame, increasing seaward, $\mathrm{m}$.

A demeaned, normalized signal.

indication of a variable modeled by an equilibrium model.

- alongshore averaging (appendix).

$\checkmark$ alongshore asymmetric part of a signal in an embayment (appendix).

Acknowledgments

The present research was funded through the DFG (Deutsche

Forschungsgemeinschaft) International Research Training Group INTERCOAST (Integrated Coastal Zone and Shelf-Sea Research) and MARUM (Center for Marine Environmental Sciences). Wave buoy data were kindly provided by the Bay of Plenty Regional Council (NZ) The Land Information New Zealand (LINZ) government department provided the bathymetric data used in the wave model, and the National Oceanic and Atmospheric Administration (NOAA, USA) provided the wave hindcast data. The CamEra system was installed by the Waikato Regional Council. The authors would like to thank George Payne (NIWA) for providing the images and maintaining the CamEra system and Wietse van de Lageweg for digitizing the shoreline and barline data used in the present paper. As well, the authors want to acknowledge Dirk Immenga for his precious assistance in collecting local wave data and beach profiles at Tairua Beach in 2011. The data used in this study are available on PANGAEA (http://www.pangaea.de) using the doi of the present publication. We deeply acknowledge four anonymous reviewers for their helpful comments on an early version of the manuscript.

\section{References}

Almar, R., G. Coco, K. R. Bryan, D. Huntley, A. Short, and N. Sénéchal (2008), Video observations of beach cusp morphodynamics, Mar. Geol., 254(3-4), 216-223, doi:10.1016/j.margeo.2008.05.008.

Alvarez-Ellacuria, A., A. Orfila, L. Gómez-Pujol, G. Simarro, and N. Obregon (2011), Decoupling spatial and temporal patterns in short-term beach shoreline response to wave climate, Geomorphology, 128(3-4), 199-208, doi:10.1016/j.geomorph.2011.01.008.

Ashton, A., A. B. Murray, and O. Arnoult (2001), Formation of coastline features by large-scale instabilities induced by high-angle waves, Nature, 414(6861), 296-300, doi:10.1038/35104541.

Ashton, A. D., and A. B. Murray (2006), High-angle wave instability and emergent shoreline shapes: 1. Modeling of sand waves, flying spits, and capes, J. Geophys. Res., 111, F04011, doi:10.1029/2005JF000422.

Blossier, B., K. R. Bryan, and C. Winter (2015), Simple pocket beach rotation model derived from linear analysis, in Proceedings of the Coastal Sediments 2015, pp. 65-77, World Scientific, San Diego, Calif., doi:10.1142/9789814689977_0032.

Blossier, B., K. R. Bryan, C. J. Daly, and C. Winter (2016), Nearshore sandbar rotation at single-barred embayed beaches, J. Geophys. Res. Oceans, 121, 2286-2313, doi:10.1002/2015JC011031.

Bogle, J., K. R. Bryan, K. Black, T. Hume, and T. Healy (2001), Video observations of rip formation and evolution, J. Coastal Res., 34, $117-127$. Booden, M. A., I. E. Smith, J. L. Mauk, and P. M. Black (2012), Geochemical and isotopic development of the Coromandel Volcanic Zone, Northern New Zealand, since 18 Ma, J. Volcanol. Geotherm. Res., 219-220, 15-32, doi:10.1016/j.jvolgeores.2012.01.005.

Booij, N., R. C. Ris, and L. H. Holthuijsen (1999), A third-generation wave model for coastal regions: 1. Model description and validation, J. Geophys. Res., 104(C4), 7649-7666, doi:10.1029/98JC02622.

Bowen, A. J., D. L. Inman, and V. P. Simmons (1968), Wave "set-down" and set-up, J. Geophys. Res., 73(8), 2569-2577, doi:10.1029/JB073i008p02569.

Bryan, K. R., R. Foster, and I. MacDonald (2013), Beach rotation at two adjacent headland-enclosed beaches, in Proceedings of the 12th International Coastal Symposium, edited by D. C. Conley et al., pp. 2095-2100, J. Coastal Res. Spec. Issue 65, Plymouth, England, doi:10.2112/SI65-354.1.

Castelle, B., and G. Coco (2012), The morphodynamics of rip channels on embayed beaches, Continent. Shelf Res., 43, 10-23, doi:10.1016/j.csr.2012.04.010.

Castelle, B., B. Ruessink, P. Bonneton, V. Marieu, N. Bruneau, and T. Price (2010a), Coupling mechanisms in double sandbar systems. Part 1: Patterns and physical explanation, Earth Surf. Process. Landforms, 35(4), 476-486, doi:10.1002/esp.1929.

Castelle, B., B. Ruessink, P. Bonneton, V. Marieu, N. Bruneau, and T. Price (2010b), Coupling mechanisms in double sandbar systems. Part 2: Impact on alongshore variability of inner-bar rip channels, Earth Surf. Process. Landforms, 35(7), 771 -781, doi:10.1002/esp.1949.

Chaibi, M., and M. Sedrati (2009), Coastal erosion induced by human activities: The case of two embayed beaches on the Moroccan coast, J. Coastal Res., 56, 1184-1188.

Clarke, D. J., and I. G. Eliot (1982), Description of littoral, alongshore sediment movement from empirical eigenfunction analysis, J. Geol. Soc. Austr., 29(3-4), 327-341, doi:10.1080/00167618208729217.

Coco, G., K. R. Bryan, M. O. Green, B. G. Ruessink, I. M. J. van Enckevort, and I. L. Turner (2005), Video observations of shoreline and sandbar coupled dynamics, in Coastal Living-Living Coast; Australasian Conference; Proceedings, Barton, A.C.T., edited by M. R. Townsend and D. Walker, pp. 471-476, Institution of Engineers, Australia.

Dai, Z. J., J. Y. Chen, J. Z. Du, and C. C. Li (2008), Seasonal changes of sandbar behavior in Nanwan Beach, South China, J. Coastal Res., 24, 1209-1216, doi:10.2112/06-0773.1.

Daly, C. J., K. R. Bryan, and C. Winter (2014), Wave energy distribution and morphological development in and around the shadow zone of an embayed beach, Coast. Eng., 93(0), 40-54, doi:10.1016/j.coastaleng.2014.08.003. 
Daly, C. J., C. Winter, and K. R. Bryan (2015), On the morphological development of embayed beaches, Geomorphology, 248, 252-263, doi:10.1016/j.geomorph.2015.07.040.

Davidson, M., R. Lewis, and I. Turner (2010), Forecasting seasonal to multi-year shoreline change, Coast. Eng., 57(6), 620-629, doi:10.1016/j.coastaleng.2010.02.001.

Davidson, M., K. Splinter, and I. Turner (2013), A simple equilibrium model for predicting shoreline change, Coast. Eng., 73(0), 191-202, doi:10.1016/j.coastaleng.2012.11.002.

Flor, G., and G. Flor-Blanco (2005), An introduction to the erosion and sedimentation problems in the coastal regions of Asturias and Cantabria (NW Spain) and its implications on environmental management, J. Coastal Res., 49, 58-63.

Gallop, S., K. Bryan, G. Coco, and S. Stephens (2011), Storm-driven changes in rip channel patterns on an embayed beach, Geomorphology, 127(3-4), 179-188, doi:10.1016/j.geomorph.2010.12.014.

Grasso, F., H. Michallet, E. Barthélemy, and R. Certain (2009), Physical modeling of intermediate cross-shore beach morphology: Transients and equilibrium states, J. Geophys. Res., 114, C09001, doi:10.1029/2009JC005308.

Guedes, R. M. C., K. R. Bryan, G. Coco, and R. A. Holman (2011), The effects of tides on swash statistics on an intermediate beach, J. Geophys. Res., 116, C04008, doi:10.1029/2010JC006660.

Hannachi, A., I. T. Jolliffe, and D. B. Stephenson (2007), Empirical orthogonal functions and related techniques in atmospheric science: A review, Int. J. Climatol., 27(9), 1119-1152, doi:10.1002/joc.1499.

Hansen, J. E., and P. L. Barnard (2010), Sub-weekly to interannual variability of a high-energy shoreline, Coast. Eng., 57(11-12), 959-972, doi:10.1016/j.coastaleng.2010.05.011.

Harley, M. D., I. L. Turner, A. D. Short, and R. Ranasinghe (2011), A reevaluation of coastal embayment rotation: The dominance of cross-shore versus alongshore sediment transport processes, Collaroy-Narrabeen Beach, southeast Australia, J. Geophys. Res., 116, F04033, doi:10.1029/2011JF001989.

Harley, M. D., I. L. Turner, and A. D. Short (2015), New insights into embayed beach rotation: The importance of wave exposure and cross-shore processes, J. Geophys. Res. Earth Surf., 120, 1470-1484, doi:10.1002/2014JF003390.

Hart, D. E., and K. R. Bryan (2008), New zealand coastal system boundaries, connections and management, N. Z. Geogr., 64(2), 129-143, doi:10.1111/j.1745-7939.2008.00133.x.

Healy, T., and T. Soomere (2008), Managed retreat - Is it really an option for mitigation of chronic erosion and storm surge flooding?, in Solutions to Coastal Disasters Conference Proceedings, pp. 456-462, Am. Soc. of Civil Eng., Oahu, doi:10.1061/40968(312)41.

Jara, M., M. González, and R. Medina (2015), Shoreline evolution model from a dynamic equilibrium beach profile, Coast. Eng., 99, 1-14, doi:10.1016/j.coastaleng.2015.02.006.

Karunarathna, H., J. M. Horrillo-Caraballo, R. Ranasinghe, A. D. Short, and D. E. Reeve (2012), An analysis of the cross-shore beach morphodynamics of a sandy and a composite gravel beach, Mar. Geol,, 299-302(0), 33-42, doi:10.1016/j.margeo.2011.12.011.

Komar, P. D., and D. L. Inman (1970), Longshore sand transport on beaches, J. Geophys. Res., 75(30), 5914-5927.

Kuriyama, Y., and S. Yanagishima (2016), Investigation of medium-term barred beach behavior using 28-year beach profile data and rotated empirical orthogonal function analysis, Geomorphology, 261, 236-243, doi:10.1016/j.geomorph.2016.03.002.

Larson, M., M. Capobianco, and H. Hanson (2000), Relationship between beach profiles and waves at Duck, North Carolina, determined by Canonical Correlation Analysis, Mar. Geol., 163, 275-288, doi:10.1016/S0025-3227(99)00119-X.

Lippmann, T., and R. Holman (1990), The spatial and temporal variability of sand bar morphology, J. Geophys. Res., 95(C7), 11,575-11,590.

Loureiro, C., Ó. Ferreira, and J. A. G. Cooper (2012), Geologically constrained morphological variability and boundary effects on embayed beaches, Mar. Geol., 329-331, 1-15, doi:10.1016/j.margeo.2012.09.010.

Ludka, B. C., R. T. Guza, W. C. O'Reilly, and M. L. Yates (2015), Field evidence of beach profile evolution toward equilibrium, J. Geophys. Res. Oceans, 120, 7574-7597, doi:10.1002/2015JC010893.

Miller, J. K., and R. G. Dean (2004), A simple new shoreline change model, Coast. Eng., 51(7), 531-556, doi:10.1016/j.coastaleng.2004.05.006.

Miller, J. K., and R. G. Dean (2007a), Shoreline variability via empirical orthogonal function analysis: Part I temporal and spatial characteristics, Coast. Eng., 54(2), 111-131, doi:10.1016/j.coastaleng.2006.08.013.

Miller, J. K., and R. G. Dean (2007b), Shoreline variability via empirical orthogonal function analysis: Part II relationship to nearshore conditions, Coast. Eng., 54(2), 133-150, doi:10.1016/j.coastaleng.2006.08.014.

North, G. R., T. L. Bell, R. F. Cahalan, and F. J. Moeng (1982), Sampling errors in the estimation of empirical orthogonal functions, Mon. Weather Rev., 110(7), 699-706, doi:10.1175/1520-0493(1982)110<0699:SEITEO>2.0.CO;2.

Ojeda, E., and J. Guillén (2008), Shoreline dynamics and beach rotation of artificial embayed beaches, Mar. Geol., 253(1-2), 51-62, doi:10.1016/j.margeo.2008.03.010.

Ojeda, E., J. Guillén, and F. Ribas (2011), Dynamics of single-barred embayed beaches, Mar. Geol., 280(1-4), 76-90, doi:10.1016/j.margeo.2010.12.002.

Plant, N., K. Todd Holland, and R. Holman (2006), A dynamical attractor governs beach response to storms, Geophys. Res. Lett., 33, L17607, doi:10.1029/2006GL027105.

Plant, N. G., R. A. Holman, M. H. Freilich, and W. A. Birkemeier (1999), A simple model for interannual sandbar behavior, J. Geophys. Res., 104(C7), 15,755-15,776, doi:10.1029/1999JC900112.

Plant, N. G., S. G. J. Aarninkhof, I. L. Turner, and K. S. Kingston (2007), The performance of shoreline detection models applied to video imagery, J. Coastal Res., 23(3), 658-670, doi:10.2112/1551-5036(2007)23[658:TPOSDM]2.0.CO;2.

Price, T., and B. Ruessink (2011), State dynamics of a double sandbar system, Continent. Shelf Res., 31(6), 659-674, doi:10.1016/j.csr.2010.12.018.

Ratliff, K. M., and A. B. Murray (2014), Modes and emergent time scales of embayed beach dynamics, Geophys. Res. Lett., 41, 7270-7275, doi:10.1002/2014GL061680.

Reeve, D. E., J. M. Horrillo-Caraballo, and V. Magar (2008), Statistical analysis and forecasts of long-term sandbank evolution at great yarmouth, \{UK\}, Estuarine Coastal and Shelf Sci., 79(3), 387-399, doi:10.1016/j.ecss.2008.04.016.

Ribas, F. F., E. Ojeda, T. Price, and J. Guillen (2010), Assessing the suitability of video imaging for studying the dynamics of nearshore sandbars in tideless beaches, IEEE Trans. Geosci. Remote Sens., 48(6), 2482-2497, doi:10.1109/TGRS.2009.2039576.

Roelvink, J., and I. Brøker (1993), Cross-shore profile models, Coast. Eng., 21(1), 163-191, doi:10.1016/0378-3839(93)90049-E.

Ruessink, B. G., G. Coco, R. Ranasinghe, and I. L. Turner (2007), Coupled and noncoupled behavior of three-dimensional morphological patterns in a double sandbar system, J. Geophys. Res., 112, C07002, doi:10.1029/2006JC003799.

Ruessink, B., L. Pape, and I. Turner (2009), Daily to interannual cross-shore sandbar migration: Observations from a multiple sandbar system, Continent. Shelf Res., 29(14), 1663-1677, doi:10.1016/j.csr.2009.05.011. 
Ruiz de Alegria-Arzaburu, A., A. Pedrozo-Acuna, J. M. Horrillo-Caraballo, G. Masselink, and D. E. Reeve (2010), Determination of wave-shoreline dynamics on a macrotidal gravel beach using canonical correlation analysis, Coast. Eng., 57(3), 290-303, doi:10.1016/j.coastaleng.2009.10.014.

Sénéchal, N., G. Coco, B. Castelle, and V. Marieu (2015), Storm impact on the seasonal shoreline dynamics of a meso- to macrotidal open sandy beach (Biscarrosse, France), Geomorphology, 228, 448-461, doi:10.1016/j.geomorph.2014.09.025.

Short, A. D. (1999), Handbook of Beach and Shoreface Morphodynamics, John Wiley, Chichester, U. K.

Short, A. D., and A. C. Trembanis (2004), Decadal scale patterns in beach oscillation and rotation Narrabeen Beach, Australia: Time series, PCA and wavelet analysis, J. Coastal Res., 20(2), 523-532.

Smith, R., and K. Bryan (2007), Monitoring beach face volume with a combination of intermittent profiling and video imagery, J. Coastal Res., 23(4), 892-898, doi:10.2112/04-0287.1.

Splinter, K. D., R. A. Holman, and N. G. Plant (2011), A behavior-oriented dynamic model for sandbar migration and 2DH evolution, J. Geophys. Res., 116, C01020, doi:10.1029/2010JC006382.

Splinter, K. D., I. L. Turner, M. A. Davidson, P. Barnard, B. Castelle, and J. Oltman-Shay (2014), A generalized equilibrium model for predicting daily to interannual shoreline response, J. Geophys. Res. Earth Surf., 119, 1936-1958, doi:10.1002/2014JF003106.

Splinter, K. D., I. L. Turner, M. Reinhardt, and G. Ruessink (2017), Rapid adjustment of shoreline behavior to changing seasonality of storms: Observations and modelling at an open-coast beach, Earth Surf. Process. Landforms, 42, 1186-1194, doi:10.1002/esp.4088.

Stockdon, H. F., R. A. Holman, P. A. Howd, and A. H. Sallenger Jr (2006), Empirical parameterization of setup, swash, and runup, Coastal Eng., 53(7), 573-588, doi:10.1016/j.coastaleng.2005.12.005.

Stokes, C., M. Davidson, and P. Russell (2015), Observation and prediction of three-dimensional morphology at a high-energy macrotidal beach, Geomorphology, 243, 1-13, doi:10.1016/j.geomorph.2015.04.024.

Turki, I., R. Medina, M. Gonzalez, and G. Coco (2013a), Natural variability of shoreline position: Observations at three pocket beaches, Mar. Geol., 338, 76-89, doi:10.1016/j.margeo.2012.10.007.

Turki, I., R. Medina, G. Coco, and M. Gonzalez (2013b), An equilibrium model to predict shoreline rotation of pocket beaches, Mar. Geol., 346(0), 220-232, doi:10.1016/j.margeo.2013.08.002.

van de Lageweg, W., K. Bryan, G. Coco, and B. Ruessink (2013), Observations of shoreline-sandbar coupling on an embayed beach, Mar. Geol., 344, $101-114$, doi:10.1016/j.margeo.2013.07.018.

van Enckevort, I., and B. Ruessink (2001), Effect of hydrodynamics and bathymetry on video estimates of nearshore sandbar position, J. Geophys. Res., 106(C8), 16,969-16,979, doi:10.1029/1999JC000167.

van Maanen, B., P. de Ruiter, G. Coco, K. Bryan, and B. Ruessink (2008), Onshore sandbar migration at Tairua Beach (New Zealand): Numerical simulations and field measurements, Mar. Geol., 253(3-4), 99-106, doi:10.1016/j.margeo.2008.05.007.

van Rijn, L., D. Walstra, B. Grasmeijer, J. Sutherland, S. Pan, and J. Sierra (2003), The predictability of cross-shore bed evolution of sandy beaches at the time scale of storms and seasons using process-based profile models, Coastal Eng., 47(3), 295-327, doi:10.1016/S0378-3839(02)00120-5.

Walters, R. A., D. G. Goring, and R. G. Bell (2001), Ocean tides around New Zealand, N. Z. J. Mar. Freshwater Res., 35(3), 567-579, doi:10.1080/00288330.2001.9517023.

Wijnberg, K. M., and J. H. Terwindt (1995), Extracting decadal morphological behaviour from high-resolution, long-term bathymetric surveys along the Holland coast using eigenfunction analysis, Mar. Geol., 126(1), 301-330, doi:10.1016/0025-3227(95)00084-C.

Wilks, D. (2011), Chapter 12-Principal Component (EOF) analysis, in Statistical Methods in the Atmospheric Sciences, vol. 100, edited by D. S. Wilks, pp. 519-562, Int. Geophys, doi:10.1016/B978-0-12-385022-5.00012-9.

Winant, C. D., D. L. Inman, and C. E. Nordstrom (1975), Description of seasonal beach changes using empirical eigenfunctions, J. Geophys. Res., 80(15), 1979-1986, doi:10.1029/JC080i015p01979.

Wright, L., and A. Short (1984), Morphodynamic variability of surf zones and beaches: A synthesis, Mar. Geol., 56(1-4), 93-118, doi:10.1016/0025-3227(84)90008-2.

Yates, M. L., R. T. Guza, and W. C. O'Reilly (2009), Equilibrium shoreline response: Observations and modeling, J. Geophys. Res., 114, C09014, doi:10.1029/2009JC005359.

Zwiers, F. W., and H. von Storch (1995), Taking serial correlation into account in tests of the mean, J. Clim., 8(2), 336-351, doi:10.1175/1520-0442(1995)008<0336:TSCIAI>2.0.CO;2. 